FY2015 $4^{\text {TH }}$ QUARTER INL/EXT-15-37250

\title{
IDAHO NATIONAL LABORATORY
}

QUARTERLY

OCCURRENCE ANALYSIS

DEEPER LEARNING THROUGH EVENT ANALYSIS 


\section{Contents}

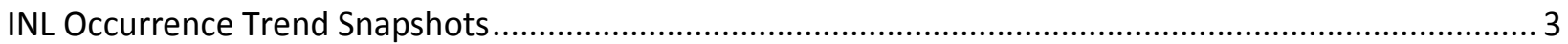

$4^{\text {th }}$ Qtr FY-15 KEY LESSONS LEARNED ISSUED BY INL ORGANIZATIONS ................................... 4

$4^{\text {th }}$ Qtr FY-15 IDENTIFICATION OF RECURRING EVENTS ....................................................... 8

$4^{\text {th }}$ Qtr FY-15 ANALYSIS OF PERFORMANCE COMPARED TO OTHER COMPLEX REPORTING ........9

$4^{\text {th }}$ Qtr FY-15 GROUP 1 - OPERATIONAL EMERGENCIES ..................................................... 10

$4^{\text {th }}$ Qtr FY-15 GROUP 2 - PERSONNEL SAFETY AND HEALTH .............................................. 10

$4^{\text {th }}$ Qtr FY-15 GROUP 3 - NUCLEAR SAFETY BASIS EVENTS.................................................. 12

$4^{\text {th }}$ Qtr FY-15 GROUP 4 - FACILITY STATUS EVENTS......................................................... 14

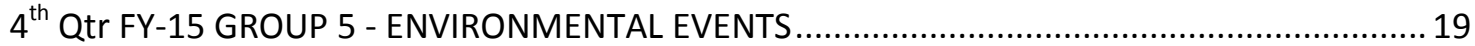

$4^{\text {th }}$ Qtr FY-15 GROUP 6 - CONTAMINATION/RADIATION CONTROL EVENTS ............................... 21

$4^{\text {th }}$ Qtr FY-15 GROUP 7 - NUCLEAR EXPLOSIVE SAFETY EVENTS.............................................. 22

$4^{\text {th }}$ Qtr FY-15 GROUP 8 - PACKAGING AND TRANSPORTATION EVENTS …................................ 22

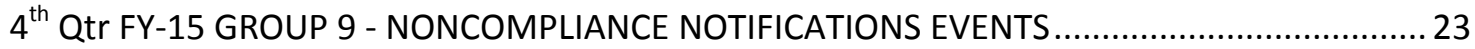

$4^{\text {th }}$ Qtr FY-15 GROUP 10 - MANAGEMENT CONCERNS AND ISSUES ........................................ 24

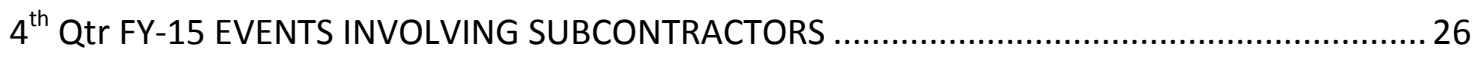

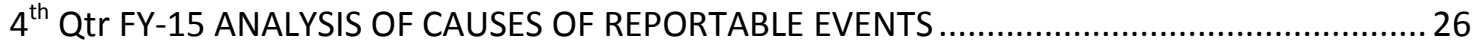

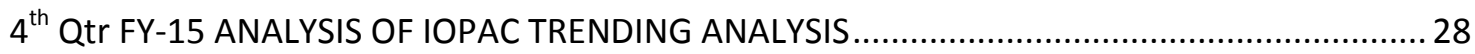


INL/EXT-15-36311

FY-15 $4^{\text {th }}$ Quarter

This report is published quarterly by the Idaho National Laboratory (INL) Quality and Performance Management Organization.

The Department of Energy (DOE) Occurrence Reporting and Processing System (ORPS), as prescribed in DOE Order 232.2,

"Occurrence Reporting and Processing of Operations

Information," requires a quarterly analysis of events, both reportable and not reportable, for the previous 12 months.

This report is the analysis of 85 reportable events (18 from the $4^{\text {th }}$ Qtr FY-15 and 67 from the prior three reporting quarters), as well as 25 other issue reports (including events found to be not reportable and Significant Category A and B conditions) identified at INL during the past 12 months $(8$ from this quarter and 17 from the prior three quarters).

Battelle Energy Alliance (BEA) operates the INL under contract

DE-AC07-051D14517.
Highlights...

The quarterly average number of reportable events at the INL increased from 15 in FY-14 to 21.3 in FY-15. Over $43 \%$ of the FY-15 events were associated with performance degradation of safety class safety significant components at the Advanced Test Reactor (ATR).

The rate of significant events (those reported as Operational Emergencies, Recurring Issues, and/or Significance Categories 1 or 2) continues to trend downward.

Over the past 24 months, the average number of days between significant occurrences continues to increase, indicating that significant events are occurring less frequently. An increase in the number of days between significant events is a positive trend.

This quarterly analysis reviews those events that were reportable through ORPS, events that did not meet ORPS reporting thresholds, some conditions tracked in LabWay, and the causes of reportable events.

The report also provides a summary of the more significant Lessons Learned issued by INL.
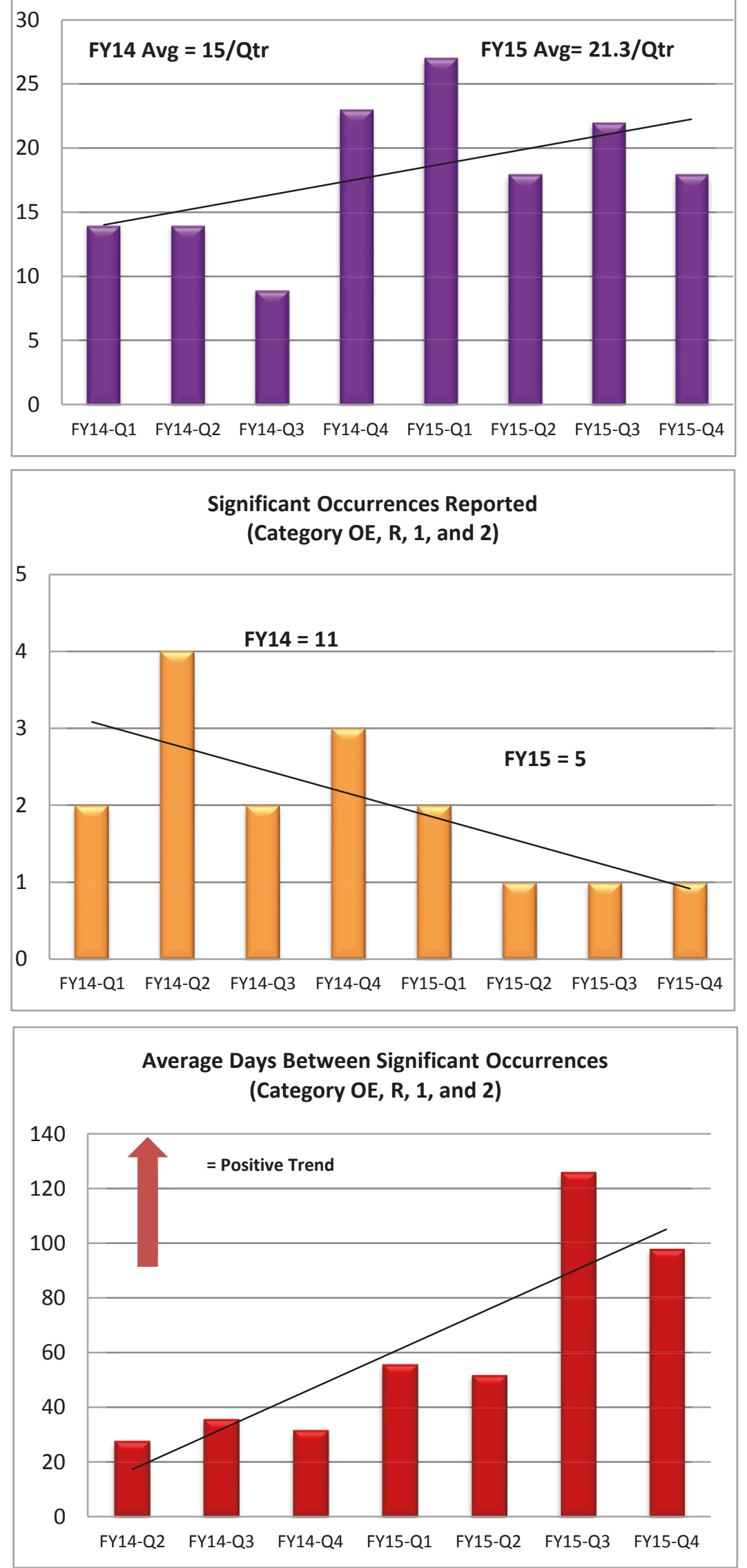


\section{INL Occurrence Trend Snapshots}

From July 1, 2015 through September 30, 2015, INL reported 18 new events to DOE, in accordance with DOE Order 232.2. These events were analyzed to determine commonalities related to: Operational Emergencies (Group 1), Personnel Safety and Health (Group 2), Nuclear Safety Basis (Group 3), Facility Status (Group 4), Environmental (Group 5), Contamination and Radiation Control (Group 6), Nuclear Explosive Safety (Group 7), Packaging and Transportation (P\&T) (Group 8), Noncompliance Notifications (Group 9), and Management Concerns (Group 10).

In addition, INL reported eight events and conditions through Initial Notification Reports (INRs) and INL's local issues tracking software (LabWay) that did not meet ORPS reporting thresholds and one event as a Significance Category B condition in LabWay.

\section{TREND SNAPSHOT}

\section{Occurrences by Facility: During the} reporting quarter, ATR saw a slight increase in the number of events reported. The number of events reported at ATR this quarter was higher than the average number reported during the past 12 months. All other areas saw a steady rate or a decline in the number of events reported.

ATR has reported $60 \%$ of the events in the past 12 months; MFC has reported $19 \%$.

\section{TREND SNAPSHOT}

\section{Occurrences by Reporting Criteria:}

During FY-15, INL has experienced the majority of events related to: Group 4, Facility Status (53\%) (see Group 4 discussion), followed by Group 2, Personnel Safety and Health (18\%), and Group 10,

Management Concerns (14\%). Comparative analysis to the balance of the DOE complex is shown in the chart to the right and is explained in each section of the report that follows. The balance of the DOE Compex reports the majority of events in Group 10 (29\%), followed by Group 2 (24\%), and Group 3, Nuclear Safety Basis (19\%).

\section{Occurrence Reports by Facility}

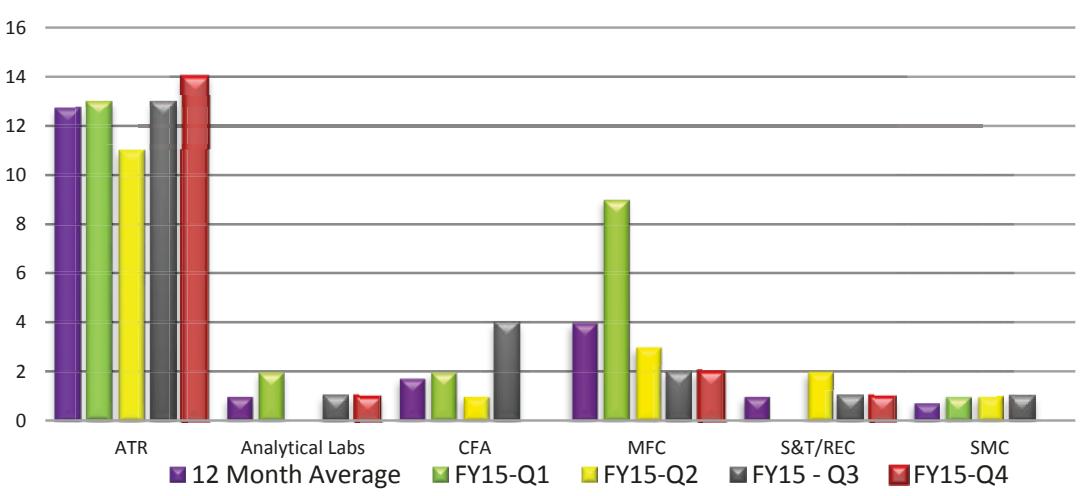

Occurrence by Reporting Criteria

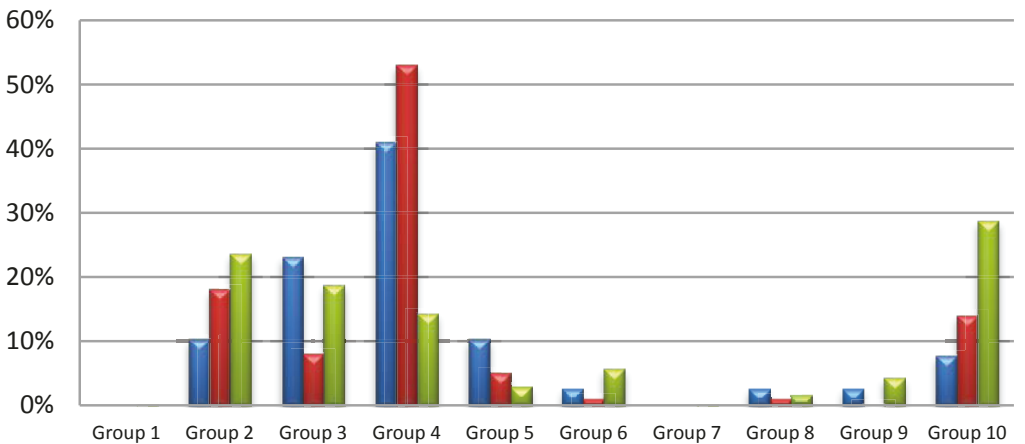

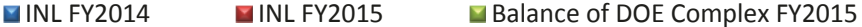




\section{SNAPSHOT}

Lessons Learned Events: Continuing in the $4^{\text {th }}$ Qtr FY-15, the use of Lessons Learned through OPEXShare showed improvement with many more employees signing up to receive Lessons Learned. Internalizing lessons learned (as indicated by responses entered into OPEXShare) show that INL organizations are using the lessons to improve operations at the Laboratory; active internalization (e.g., using lessons at meetings, incorporating lesson into work documents, and issuing the lesson as a required reading assignment) of lessons also increased. INL issued nine lessons learned during the quarter.

The INL Lessons Learned Program is an integral part of the feedback and improvement processes required by DOE. Operational excellence requires the use of internal and external operating experience information (OEI) to minimize the likelihood of undesirable behaviors and promote noteworthy practices. Lessons learned are systematically evaluated and implemented to continuously improve performance. INL embraces the philosophy that lessons learned are lessons applied.

During $4^{\text {th }}$ Qtr FY-15, INL used internally generated and/or shared lessons from other sites to improve operations and learn from other's events or mistakes. Of this data, nine lessons were internally generated and entered into the INL database to be shared across the INL prior to migration to OPEXShare. Some of the nine lessons shared by INL are summarized below:

\section{Detector Housing Lid Blows off of Infrared Spectrometer}

Lesson 2015-0027

At the Energy Innovation Laboratory (EIL); a researcher returned to the laboratory to find that the detector compartment lid on a Fourier Transform Infrared Spectrometer had blown off during an overnight data collection campaign.

The researcher was using a detector in the instrument that requires cooling via addition of liquid nitrogen. There is a small screw cap that goes over the detector fill hole, which in turn threads into the detector compartment lid. The screw cap had no O-rings. In the detector compartment there was a bellows with O-rings on the top and bottom between the detector and the compartment lid intended to keep air from entering the purged detector compartment. The screw cap was similarly intended to keep water vapor from condensing into the detector dewar and normally sits without engaging the threads.

The researcher was concerned about the liquid nitrogen evaporation rate, as noted by a drop in sensitivity sooner than anticipated. To address this loss of sensitivity, the researcher refilled the detector dewar and slightly engaged the threads on the screw lid to attempt to slow the evaporation of the nitrogen. The researcher then left for the night.

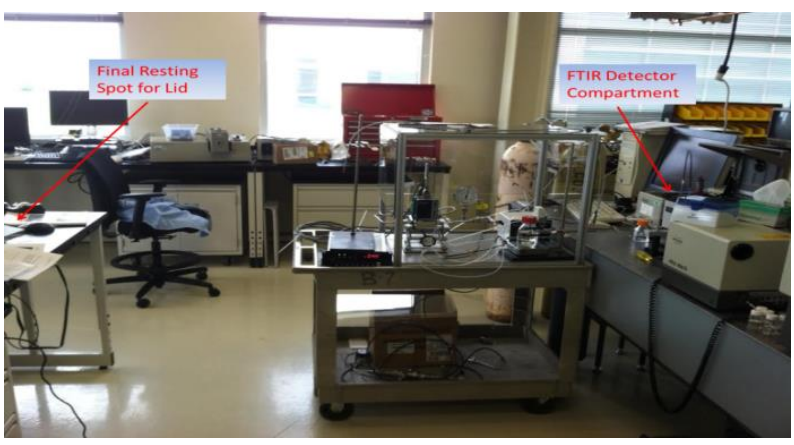

During the night, pressure began to build in the detector dewar and, because of the manner in which the lid was attached, the pressure was unable to be released by the bellows between the detector and the compartment lid or through the screw threads. As a result of the pressure buildup, the lid blew off, coming to a landing several feet away from the detector. The laboratory was unoccupied at the time of the event and no one was injured; the instrument still functions as designed.

\section{What We Can Learn:}

- Inadequate instruction: Although the researcher was briefed on the activity of filling the detector and what to 
expect when observing/performing the task, more emphasis on the potential for pressure buildup if the screw cap is engaged could have been helpful.

There is no substitute for thorough briefing and instruction. The briefing/instruction should take into consideration all things that can go wrong, even those with a small likelihood of occurring.

- Inadequate vendor documentation: Prior to leaving for the night, the researcher consulted the vendor manuals and noted no warning statements or labels for pressure buildup if the screw cap was engaged. The researcher, therefore, assumed that there was some form of pressure release or simple venting to the detector compartment. After the incident, the vendor was consulted and the lack of appropriate warnings and documentation was brought to their attention. They acknowledged this and agreed to reassess their documentation.

Vendor manuals may be incomplete as vendors can overlook potential issues, particularly if it is "routine." Look at vendor manuals with a critical eye for oversights and omissions.

- Poor design: The bellows with the O-rings that are simply intended to keep air out of the sample compartment can also create issues as they expand under pressure, tightening the seal rather than releasing the pressure. Also as a means of preventing water from condensing in the detector, other vendors use a simple loose fitting plug rather than something with threads.

If a poor design feature is noted on a commercial instrument, if possible, take corrective action to fix the problem before a problem occurs. A simple loose fitting nylon "plug" to replace the screw cap would have eliminated the problem and been just as effective as the normally loosely placed screw cap.

\section{Arc Flash During Preventive Maintenance of Vacuum Circuit Breakers}

Lesson 2015-0025

During the week of April 20, 2015, three INL Power

Management linemen began a three year preventive maintenance package to test Vacuum Breakers \#B41, \#B42, and \#B44 at the Central Facilities Area (CFA) Substation. The breakers are part of a 12.5 kilovolt $(\mathrm{kV})$ bus that provides power to the CFA area. On the afternoon of April 23, work proceeded on Breaker \#B44.
While performing the work, Lineman \#1 was using a shotgun (hot stick) to remove a ground off Phase A of Breaker \#B44. During the process of moving the ground from one phase and placing it to another phase, the ground cable became hung up on the corner of the cabinet of Breaker \#B44. Linemen \#2 and \#3 were in front of the breakers preparing for hi-pot testing of the breaker. Lineman \#1 tried two to three times to dislodge the wire using a flipping motion, which ultimately resulted in the ground wire inadvertently contacting an overhead energized $12.5 \mathrm{kV}$ electrical line above adjacent Breaker \#B42. The contact with the energized line resulted in an arc flash. No persons were injured as a result of the flash.

Issues identified through the resulting cause analysis were as follows:

- Loss of situational awareness: Linemen \#1 allowed his attention to be diverted to the ground cable being hung up instead of the live electrical line overhead, allowing the ground cable to breach the 2 -ft. 2-in. minimum approach distance for Breaker \#B42.

In addition, Lineman \#2 lost situational awareness when he did not perform his functions as a spotter to ensure Lineman \#1 continued to work outside the minimum approach distance defined in the work document.

- Work package planning and scoping did not adequately identify and mitigate the hazard of maintaining the minimum approach distance even though the hazard was recognized. Maintaining situational awareness was accepted as the control to mitigate the hazard.

- Personnel involved were highly experienced and comfortable knowing the job had been performed successfully every three years for several decades.

- Even though the unmitigated hazard was recognized and discussed during the pre-job briefing, personnel did not question or request additional controls on the hazard. Workers were overly sensitive to maintaining power reliability and accepted additional risk rather than reroute power or take adjacent equipment out-of-service.

\section{What We Can Learn:}

- Exhaust all means to eliminate or mitigate hazards through engineering controls rather than rely on experience and administrative controls.

- Work planning for legacy work processes should be scrutinized, even if historically very successful, to ask 
more questions, and potentially mitigate previously accepted hazards.

- Self-imposed performance standards by good workers can lead to risk acceptance in the field.

\section{Permitted Wastewater Ditch Altered During Fire Water Line Upgrade Construction Activities}

Lesson 2015-0029

On August 6, 2015, Materials and Fuels Complex (MFC)

Environmental personnel were walking along the west side of MFC reviewing fire water system construction activities when it was observed that a trench had been cut through a permitted industrial wastewater ditch (Ditch C). In addition, soil had been added to a portion of the ditch preventing flow to the industrial wastewater pond outside the west perimeter fence. At the request of Security, dirt from excavation activities was used to cover cattails along the southern end of the ditch, preventing discharged water from flowing as intended. MFC Environmental performed a review of the environmental checklist and found that the damming activity had not been described. The State Department of Environmental Quality (DEQ) was informed of the event. The regulator does not consider this to be a modification of the permitted structure if the ditch is returned to its previous condition following testing and backfill of the TREAT fire water line.

\section{What We Can Learn:}

- Proper work planning should consider all aspects of work being performed. In this instance, work planning did not properly consider the impact of dirt generation and placement.

- The ditch was not identified, via postings or plant drawings, as a permitted structure. It is important to identify permitted structures/areas to provide defensein-depth. Configuration management is essential for work planning.

\section{Wildland Fire Near Miss with a Disconnected Power \\ Line}

Lesson 2015-0033

On the evening of June 9, 2015, a small wildland fire ignited on the INL site near Highway 20/26 necessitating a response by the INL Fire Department. Two wildland units, along with a battalion chief vehicle, were dispatched.

Upon arrival, the Battalion Chief established a Unified Command with the Arco Fire Department, who was already on scene. They evaluated the fire and formulated a response plan. The Engine Captains were given assignments by the
Incident Commander then briefed their crews and initiated fire suppression actions. As Wildland Unit \#1 was advancing along the east flank of the fire, a low-hanging power line was observed by the Captain. All fire personnel were directed to fall back to the highway. Contact was not made with the line, however; fire department vehicles came within approximately 25 feet of the low-hanging $69 \mathrm{kv}$ line.

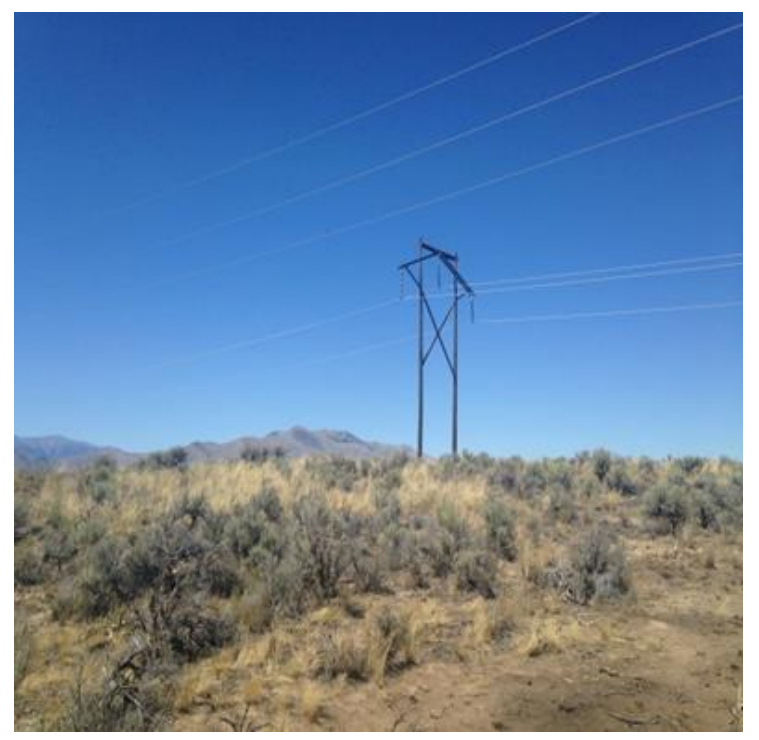

Some things that contributed to the near miss were:

- This was the first INL wildland fire of the 2015 season; and upon arrival, the fire was smaller than reported which may have provided a lessened risk perception. A number of environmental factors made it difficult to adequately assess power line condition including: dusk and the dark skies, storm clouds moved in, mountains on the horizon/backdrop, and a strong wind blowing from the north kicking up dust and smoke.

- Arco fire apparatus were already on scene and had initiated attack, which complicated communications. This may have led to Incident Command relaxing scene sizeup and briefing responsibilities.

- There are two sets of lines that run parallel to the highway, a $230 \mathrm{kv}$ line and a $69 \mathrm{kv}$ line. When looking at these lines, it is difficult to distinguish which line is connected to which pole and recognize a line that has been disconnected from the insulator and sagging.

\section{What We Can Learn:}

- Improve risk perception and implement conservative decisions when operating near power lines. Personnel sized up power lines but did not account for each conductor and not recognizing the sagging line. Apply power line safety provisions of the National Wildfire 
Coordinating Group (NWCG) Incident Response Pocket Guide after a disciplined assessment of power line condition.

- Conduct face-to-face briefings with all workers regardless of situation and familiarity of the work. Ask if there are any questions from anyone at the completion of the briefing.

- Maintain situational awareness at all times during any type of hazardous work.

\section{Drilling Radiation Hardened Experiments} Lesson 2015-0031

In preparation for shipping irradiated experiments from ATR to the Hot Fuel Examination Facility (HFEF), experiments are size reduced in the Dry Transfer Cubicle (DTC) so they could be placed into the GE-2000 Cask Insert for transport. During Advanced Graphite Capsule (AGC-3) experiment sizing operations in the DTC at the ATR, several setscrews needed to be installed into the highly irradiated 28 foot long experiment; in order to prevent the capsules from separating from the experiment shroud after being cut, several holes needed to be drilled using a standard twist drill bit, and set screws installed. Drilling did as new and in good condition prior did not go as planned because the drill bits (which were verified to use) would not penetrate the experiment. Not being able to drill the holes meant that the follow-on sizing steps could not be performed. This was especially concerning because, after the experiment was lowered into the DTC, extremely high radiation fields existed, making corrective options limited.

Experiment Engineers did not fully understand why the drill bit was not penetrating into the experiment, but believed it was due to radiation hardening of the experiment metal casing or because of the angled entry of the drill bit into the experiment. Work was paused for a short period of time while a solution to the issue was identified. To compensate for the potential issues stated above, a step drilling process was used. This involved using a smaller drill bit prior to using the planned drill bit. Using the smaller drill bit increased the drilling pressure per square inch and enabled the bit to penetrate the material without any system modifications.

This method proved to be successful. After sizing, Experiment Engineering determined that it was not practical to account for radiation hardening of experiment metal. However, a rack-and-pinion type action was investigated as a potential improvement to eliminate drill bit angled entry issue.

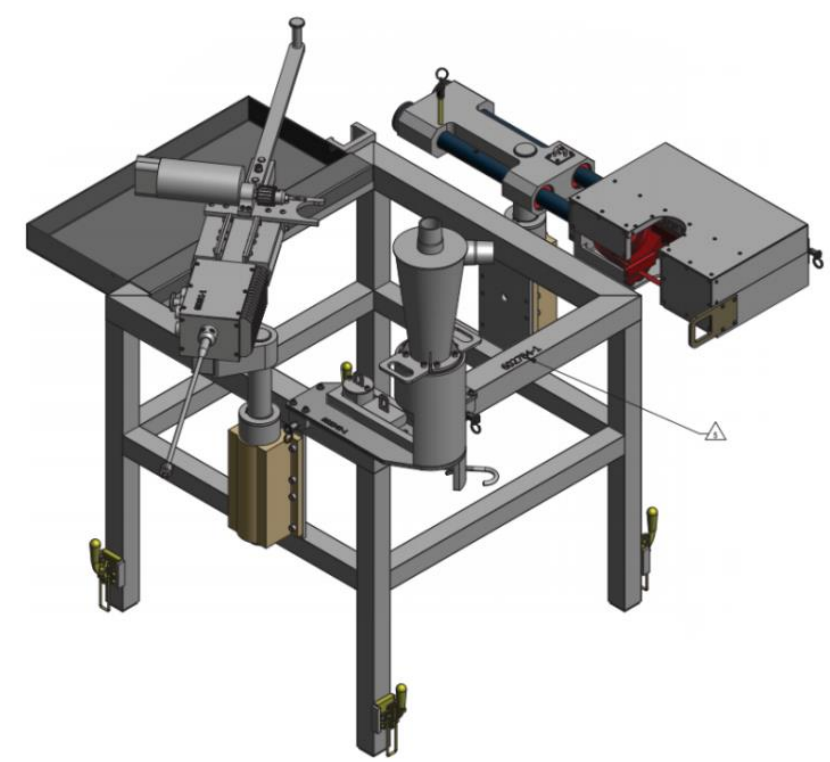

As shown in the illustration, the DTC Experiment Sizing Frame used a swivel arm that swings the bit into the experiment (not shown). Experiment Engineering determined a linear type drilling system would work better with the process. It was also found that a magnetic (type) drill had best potential to improve the drilling performance without adding a lot of design and fabrication costs.

\section{What We Can Learn:}

Having a questioning attitude when progress was not being made, helped to ensure successful completion through the identification of other drilling methods and the identification of a potential process improvement. 
The ORPS Subgroup of the Energy Facilities Contractors Group (EFCOG) Integrated Safety Management \& Quality Assurance Working Group developed a worksheet and corresponding flowchart to help managers and program owners walk through a logical process to arrive at a conclusion on whether an event or condition is recurring or not recurring. This worksheet was reviewed and modified to use at INL. The worksheet was incorporated into Laboratory Wide Procedure (LWP)-9301, Event Investigation and Occurrence Reporting. Training on the use of the flowchart will be completed during the $1^{\text {st }}$ Qtr FY-16.

During the reporting quarter, one recurring event was reported in ORPS under report NE-ID--BEA-ATR-2015-0038, Advanced

Test Reactor Deep Well Pump \#3 Diesel Generator MP-3000 Protection Relay Failure. On September17, 2015, the ATR Shift Supervisor notified ATR Management that the MP-3000 protection relay installed on the breaker for \#3 deep well pump (DWP) was discovered to have an error code which would prevent the DWP from starting. The MP-3000 is a programmable circuit protection device that requires power to maintain its setpoint programming. The MP-3000 for the \#3 DWP is continuously powered by control power fed from TRA608.

Following discovery of this condition, ATR management determined the event to be recurring based on two additional events. On January 26, 2015, the Deep Well \#3 MP-3000 protection relay had lost its settings, showing an error, either due to failed "battery" circuit or system memory. The relay had not been powered on for $\sim 200$ days, due to extended outages and had lost its charge. The relay was reprogrammed and a justification for continued use was written noting that it needed to be powered on more regularly. This event was reported under ORPS NE-ID-BEA-ATR-2015-0004.

Then on April 20. 2015, the Deep Well \#3 MP-3000 protection relay failed again. A temporary modification was installed to keep the relay powered at all times. The relay was also to be replaced; however, the newly ordered relay from Eaton arrived unacceptable for use. With the temporary modification still in place, it was believed that even though the condition of the relay was deteriorating, since it was now always powered, it would continue to perform. This second failure was reported under ORPS NE-ID--BEA-ATR-20150015. The third failure indicated that the compensatory and corrective actions to address the first two failures were not effective in preventing another failure. 

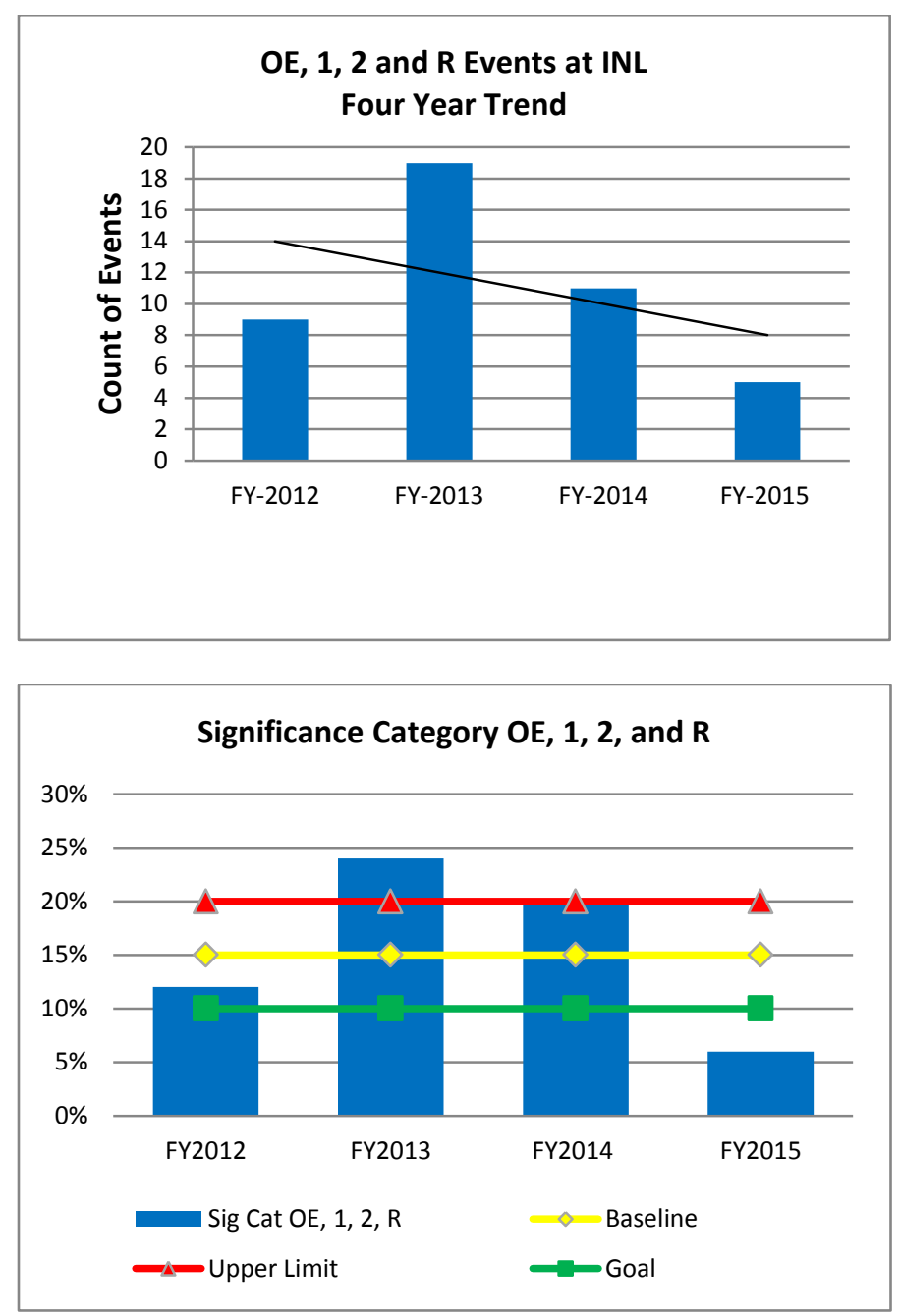

INL established a set of performance metrics to monitor events by their significance. The measures compare INL events to those reported at other facilities within the DOE complex. Baseline data was derived from complex-wide reporting of 5,630 events in the ORPS database between 2009 and August 2014. INL's goal is to experience a downward trend in the number of Significance Category OE, 1,2 , and R events occurring at INL. INL's performance metrics are as follows:
Green: Less than $10 \%$ of the events reported at INL are significant (OE, Sig Cat, 1, 2, or R); Yellow: Greater than $10 \%$ and less than $20 \%$ of the events reported at INL are significant (OE, Sig Cat 1, 2, or R); and Red: Greater than $20 \%$ of the events reported at INL are significant (OE, Sig Cat, 1, 2, or R). Control Limits for Significance Category OE, 1, 2, and R events were set at $+10 \%$ of baseline.

Additionally, INL monitors events by significance category to determine if INL reporting is consistent with reporting at other DOE facilities.

As shown in the first chart to the left, INL continues to experience a downward trend in the number of significant events (Sig Cat OE, 1, 2, and R) occurring at the INL over the past four years, with INL seeing fewer significant events than reported last fiscal year.

During FY-13 and FY-14, INL reported a greater percentage of significant reportable events (Sig Cat OE, 1, 2, and R), as compared to other DOE facilities (see next chart). However, FY-15 data shows the INL to be below our goal of less than $10 \%$ of events reported at INL as significant events.

INL is experiencing a lower percentage of Significance Category 3 events than those experienced throughout the rest of the complex. During FY-15, INL reported $25 \%$ of events as Significance Category 3, compared to $43 \%$ across the complex; and $69 \%$ of INL reportable were categorized as Significance Category 4 events. This is higher than the complex average of $42 \%$.

Analysis on how INL measures up to the balance of the complex in each of the reporting criteria groups is provided throughout this report. 
There were no operational emergencies reported during the $3^{\text {rd }}$ quarter of FY-15. The last operational emergency was reported in April 2012, when boron triflouride gas leaked from a neutron detector (NE-ID-BEA-INLLABS-2012-0003). The rate of occurrences of operational emergencies continues to trend at zero.

When compared to the balance of the DOE complex, the rate of occurrence of these types of events at INL is consistent with those reported elsewhere. So far in FY-15, two Operational Emergencies were reported throughout the DOE Complex, equating to less than $1 / 4$ of a percent of the total events reported. The INL is consistent with the rest of the DOE Complex in that none (0\%) of INL events were reported in the Group 1 reporting group.

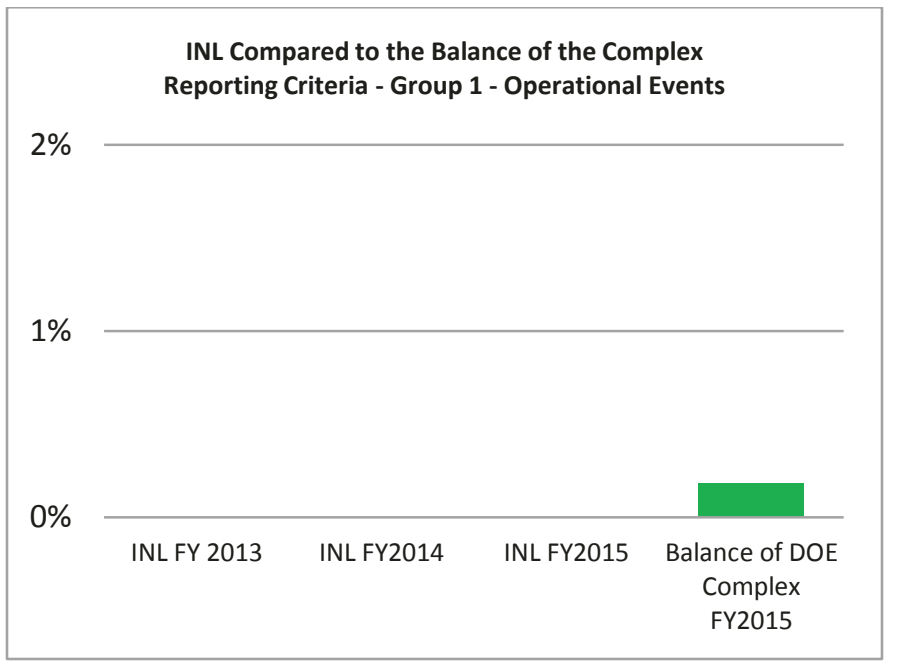

\section{$4^{\text {th }}$ Qtr FY-15 GROUP 2 - PERSONNEL SAFETY AND HEALTH}

\section{TREND SNAPSHOT}

Personnel Safety and Health Events: During the $4^{\text {th }}$ Qtr FY-15, there were no reportable events related to personnel safety and health (e.g., occupational injuries, occupational exposures, fires, explosions, or hazardous energy). However, two events were reported via INRs or directly into LabWay that did not meet the ORPS thresholds, but was related to criteria in this reporting group. The rate of occurrence of reportable personnel safety and health events is trending slightly down despite two consecutive quarters ( $4^{\text {th }}$ Quarter FY-14 and $1^{\text {st }}$ Quarter FY-15) of a high number of events in this reporting group.

When compared to the balance of the DOE complex, the rate of occurrence of Group 2 events at INL was lower than that reported elsewhere in the complex during FY-15. In FY-15, $18 \%$ of INL's reportable events were reported under Personnel Safety and Health criteria. In comparison, $24 \%$ of those reported across the DOE complex fell into this reporting group.
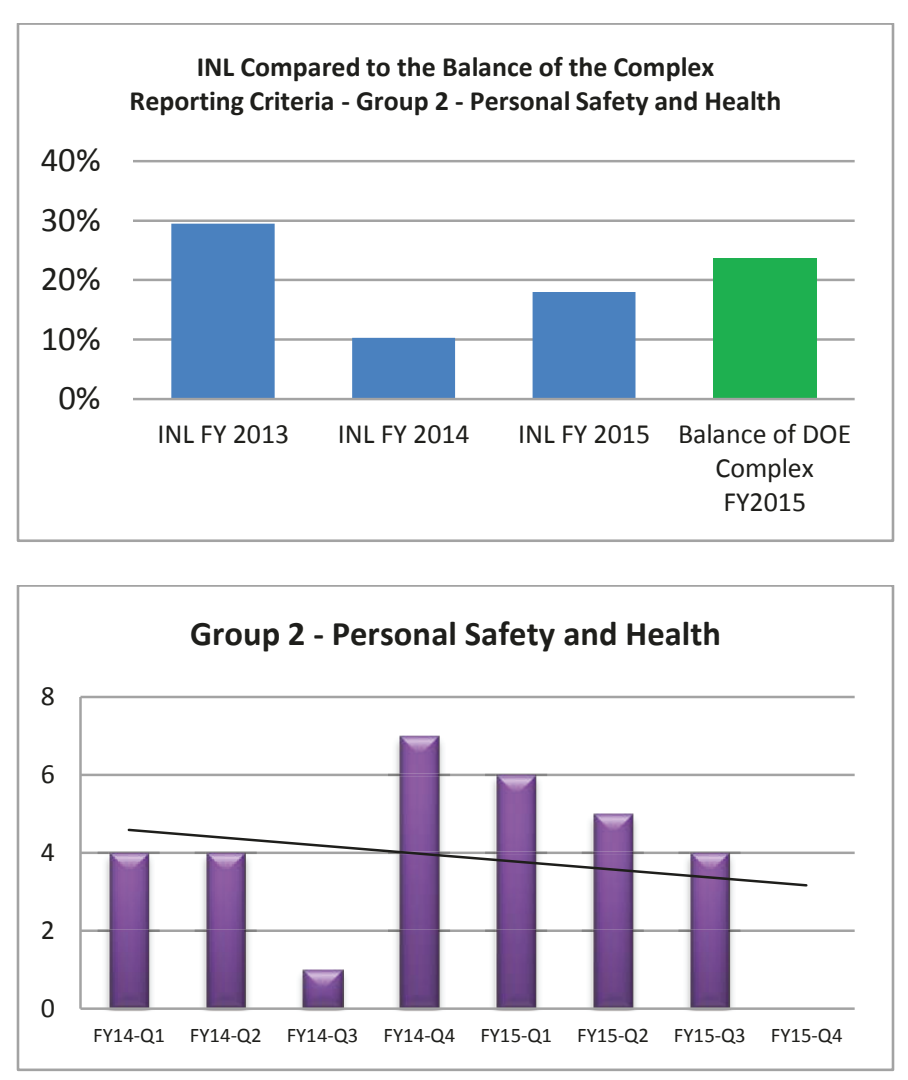

The two non-reportable events reported during the $4^{\text {th }} \mathrm{Qtr}$ FY-15 are summarized: 
CO-2015-3106

An INL Construction Field Representative (CFR) was notified that a subcontractor working near EIL had concerns related to a sprinkler line the subcontractor may have come in contact with during excavation. The subcontractor was excavating in preparation for core drilling into a utility vault. Upon arrival, the CFR resolved the sprinkJeler concern and, while still at the work site, observed a subcontracted individual core drilling into a concrete utility vault without proper personnel protective equipment (PPE). Occupational Safety and Health Administration (OSHA) requires safety glasses, respiratory protection, and hearing protection be worn during performance of such work. None of the required PPE was being worn by the worker.

The CFR requested a copy of the subcontractor's work control document but the subcontractor did not have one in their possession. The CFR and the EIL Building Specialist contacted Research and Education Campus (REC) facility management who directed them to stop work.

A formal stop work was initiated for this project, including other work scope at all other INL facilities/areas until contractual issues are resolved. In addition, the process for services subcontracts will be reviewed to ensure there are no gaps that would allow this to happen in the future.

\section{What We Can Learn:}

Oversight of work activities is essential to ensure personnel properly implement hazard controls especially when subtiered subcontractors are involved. In this event, the service subcontract did not adequately identify the Subcontract Requirement Manual (SRM) and 10 Code of Federal Regulations (CFR) 851 requirements due to the unique situation of this contract. In addition, the subcontract foreman started the work prior to notifying the Subcontractor Field Representative (SFR), resulting in a lack of oversight of sub-tiered contractors by the main Subcontractor.
SMC-CO-2015-0249

On August 23, 2015, the Specific Manufacturing Capabilities (SMC) Shift Supervisor discovered that a record sheet for an active complex Lockout/Tagout (LO/TO) showed that a Work Group Representative had signed for release of the LO/TO for his work group, but a personal lock and tag for a member of that work group was still affixed to the lock box. This condition was not in compliance with LWP-9400, Lockouts and Tagouts, with respect to the process for releasing work on a LO/TO, however, it was not a violation of the regulation. This event demonstrates the need to pay attention to detail and to ensure all necessary paperwork is completed prior to removing or authorizing removal of a LO/TO.

\section{ANALYSIS FOR RECURRING EVENTS:}

Personnel Safety and Health occurrences are the second most frequently reported event type, accounting for 15 reportable events in the last 12 months. Five of the events resulted in personnel injury; four from slips, trips, or falls and one injury sustained while moving a heavy fire rated lateral file cabinet. None of the personnel injuries were found to be recurring or similar in nature.

Two of the events were the result of an unexpected discovery of an uncontrolled hazardous energy source (either electrical or other source). Seven of the reportable events were the result of a failure to follow a hazardous energy control process. Analysis of these events did not find them to be recurring or similar in nature.

In addition to the 15 reportable events, there were eight nonreportable events during the past year that were associated with ORPS Group 2 - Employee Safety and Health criteria. A review of these eight events found no recurring themes or problem of a similar nature. 


\section{TREND SNAPSHOT}

Nuclear Safety Basis Events: Two nuclear safety basis events were reported in the $4^{\text {th }} \mathrm{Qtr} F \mathrm{FY}-15$. The rate of occurrence of nuclear safety basis events continues to tend downward over the past two years. During the past 12 months, seven events have been reported under this criteria; three were identifed at ATR and three at MFC facilities. Three were the result of a negative Unreviewed Safety Question (USQ), three were determinations of positive USQs, and one was the voilation of a credited hazard control. An analysis of the events did not reveal any commonalities that would indicate a recurring trend or recurring events.

When compared to the balance of the DOE complex, INL has reported a lower percentage of events under the Group 3 Nuclear Safety Basis criteria, than the rest of the complex. In FY-15, 8\% of INL's reportable events were reported under Nuclear Safety Basis criteria, compared to $19 \%$ across the balance of the DOE complex.

The number of INL events reported under the Nuclear Safety Basis criteria is trending downward over two years. In FY-15, Nuclear Safety Basis events have been the fourth most frequently reported event type at INL, accounting for two reportable events this quarter, and seven in the past 12 months. The two events reported during the $4^{\text {th }}$ Qtr FY-15 are summarized below.

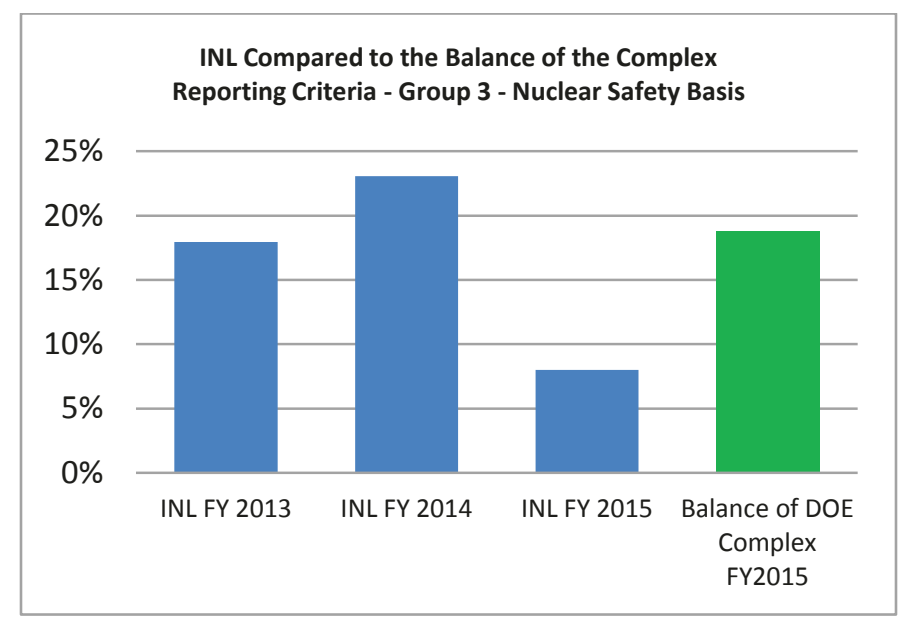

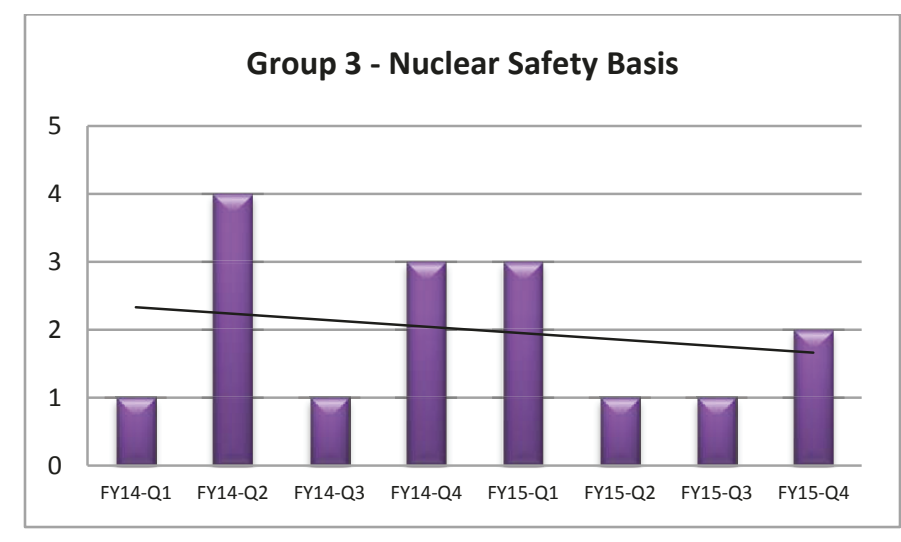

\section{Discovery of a Beryllium Container Stored with other Depleted Uranium Containers}

NE-ID--BEA-ZPPR-2015-0001 (Significance Category 3) On September 1, 2015, during the container un-stacking activities to support the packaging of containers of depleted uranium (DU) for offsite shipment, a container labeled as beryllium oxide ( $\mathrm{BeO}$ ) was discovered stored with the DU containers. The discovery came after the container had been lifted and rotated displaying the $\mathrm{BeO}$ label.

The container was immediately lowered to the floor. Work was stopped and the Nuclear Facility Manager (NFM) notified. A review of DSA-006-ZPPR-ADD-7, AC.ESS.5.ZPPR.1, $\mathrm{Be}$ and $\mathrm{BeO}$ Handling Requirements in Building 784, indicated that the movement of the BeO container, without the applicable industrial safety requirements incorporated in the handling procedure being used, constituted a violation of the evaluation of the safety of the situation (ESS) administrative control.

Zero Power Physics Reactor (ZPPR) management had informed ZPPR personnel that Building 784 was free of any 
beryllium material. This was based on the belief that all beryllium material had been removed from the facility in 2014. Multiple independent walkdowns were performed after the 2014 removal effort and no beryllium was found, which supported the original belief that the facility was free of beryllium material. ZPPR management also instructed ZPPR personnel that the pile of containers to be handled were strictly DU containers; this was based on the storage configuration of material in the facility as all material in the facility appeared to be segregated by type. Hundreds of items had been moved in recent years and nothing was found to contradict this belief. The expectations for material handling is being re-enforced and the handling procedures are being revised to prevent re-occurrence.

\section{What We Can Learn:}

Previous successes and assumptions can lead to complacency and errors. These previous successes led ZPPR operators to be comfortable handling containers prior to identifying the container label.

\section{Software Error in Structural Analysis Results in Positive PISA Reasonability Determination}

NE-ID--BEA-FMF-2015-0001 (Significance Category 4)

On June 23, 2015, it was identified to Fuel Manufacturing

Facility (FMF) management and MFC Nuclear Safety that the software program used for the seismic calculations (STAAD PRO) for the FMF vault racks contained a programming error. The error can result in non-conservative evaluations of structural members, potentially resulting in the inadequate design of structural components.

This condition potentially exists for all MFC facilities. The Potentially Inadequate Safety Analysis Reasonability Determination (PISA RD) resulted in non-conservative analytical errors in the seismic analyses related to the Fast Flux Test Facility (FFTF) storage rack and the FMF Vault Storage racks in the FMF. The safety function of the FMF storage racks is to prevent a Natural Phenomenon Hazard (NPH)-induced radioactive material release from the storage locations or a criticality in the storage array (which also may result from a seismic event), and to reduce the risk of a fireinduced radioactive material release. The error in the seismic calculations relates to the evaluation of performance related to the safety function of the safety credited racks. Therefore, the error in the performance analysis related to the storage racks constitutes an analytical error related to the safety basis and constitutes a Potentially Inadequate Safety Analysis (PISA).

An evaluation of the errors and the effect of the errors on the seismic calculations was performed via Engineering Calculations and Analysis Report (ECAR) 2953 for the FMF storage racks. The ECAR concluded that the seismic analyses are still valid and that the Performance Category classification to the structures is not negatively affected by these errors.

The safety basis for other MFC facilities were also evaluated to determine if the safety basis relied on analyses that used the affected portion of STAAD PRO. There is an analysis for the FCF Stack Monitoring Isolation Valves that is affected by the error that is not referenced. This problem is being addressed as well.

\section{Other Non-Reportable Events}

There were no additional non-reportable events related to nuclear safety basis problems documented in LabWay during the $3^{\text {rd }}$ Qtr FY-15.

\section{CO-2015-2976}

On July 23, 2015, the Fuel Conditioning Facility (FCF) NFM performed an extent of conditions evaluation on the construction process at FCF for subcontract work. The evaluation revealed that the original scope for modifications of two separate tasks underwent the INL USQ process for USQ applicability, as required by INL procedures. However, subsequent changes to the original scope were not evaluated for USQ applicability. Further investigation revealed that Job Safety Analysis (JSA) documents are not being evaluated for USQ applicability as well.

Subcontract work was stopped at FCF and appropriate reviews of the changes to the work scope and of JSAs were performed.

\section{ANALYSIS FOR RECURRING EVENTS:}

The majority of events reported under the nuclear safety basis criteria over the past year are directly attributed to increased rigor in assessing safety of the ATR following the Fukushima accident in Japan. Analysis of events reported under the ORPS Group 3 - Nuclear Safety Basis criteria, did not identify any recurring themes or problems. 


\section{TREND SNAPSHOT}

Facility Status Events: Facility status events accounted for $78 \%$ of the events reported in the $4^{\text {th }}$ Qtr FY- 15 and $53 \%$ of the events reported during FY-15. The number of events reported under this criteria increased from last quarter (11 to 14) and the rate of occurrence of facility status events continues to trend upwards over the past two years. All but one of the events occurred at ATR. Of the 14 events reported this quarter, four events at ATR were attributed to a performance degradation of a safety class or safety significant structure, system, or component when the system was required to be in operation; nine ATR events were attributed to a performance degradation of a safety class or safety significant structure, system, or component when the system was not required to be in operation, and one event at MFC Analytical Laboratory (AL) was reported as an operational event that had an adverse effect on safety. Forty-five events have been reported at the INL under this reporting criteria over the past 12 months; 37 at ATR, seven at MFC, and one at SMC.

The percentage of occurrence of Group 4 - Facility Status events at INL, is higher than that of the balance of the DOE Complex ( $53 \%$ vs $14 \%$ in $\mathrm{FY}-15$ ) and has been steadily increasing since FY-13. Seventy-one percent of those have been reported as performance degradation of a safety class Structure, System or Component (SSC) when it was not required to be in service; all of which occurred at ATR. These events are anticipated and have occurred during reactor shutdown and most often discovered during testing of equipment for restart.

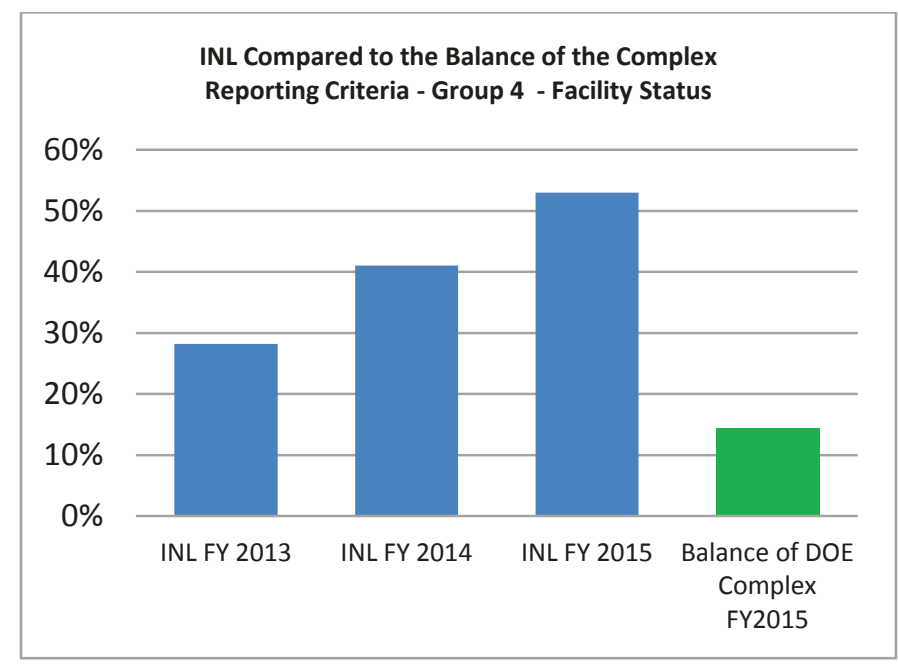

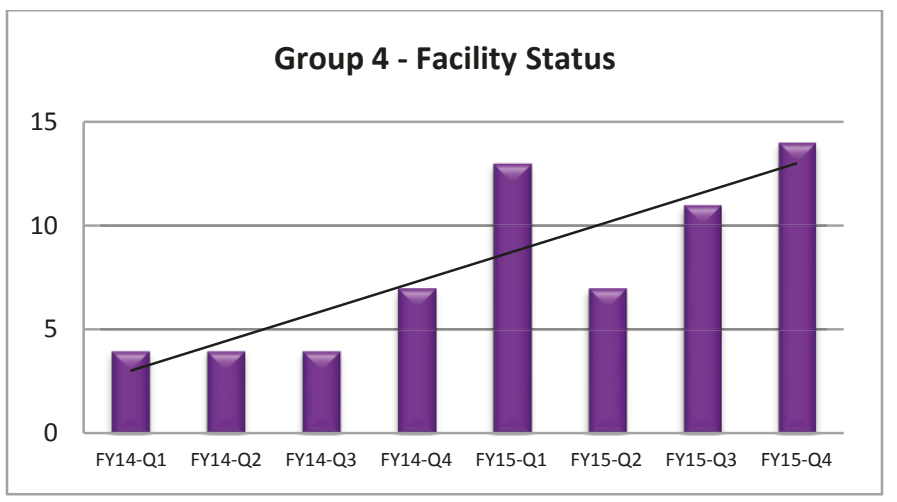

The 14 events reported under the Group 4 - Facility Status criteria during the $4^{\text {th }}$ Qtr FY-15, are summarized below. Two additional not reportable events were reported into LabWay during this quarter. These two events are also discussed below.

\section{Inadvertent Mixing of Two Suspect Liquid Tanks} NE-ID--BEA-AL-2015-0001 (Significance Category 4) On July 16, 2015, the recirculation and sample of tank \#1 occurred at the MFC AL to perform a baseline analysis of the system to determine whether there were any residual Resource Conservation and Recovery Act (RCRA) constituents in the system which might cause future transfer issues. Prior to the recirculation and sample, Tank \#2 (which had exceeded RCRA limits and was being managed separate for disposal reasons) contained approximately 180 gallons of solution. Tank \#1 (not classified as exceeding RCRA limits) contained approximately 240 gallons of solution. 
On July 17, 2015, the Shift Supervisor was contacted by the Backshift rounds man who reported an anomaly with the tank level indicators. Tank \#1 now showed a little over 400 gallons and tank \#2 showed less than 40 gallons. The Shift Supervisor informed the NFM at this time and the Shift Supervisor and NFM decided that an inspection of the tank room was warranted to ensure that the tanks themselves had not failed and that there had not been a leak. Upon inspection of the tank room, the NFM and SS noted that there did not appear to be a leak in the tank room; however, it was noticed that the valve to close off Tank \#2 from the recirculation line (which should have been shut) appeared to not be fully seated.

On July 20, 2015, a follow-up meeting was held with the mechanic who had performed the recirculation and sample in both June and July and with facility engineering. The mechanic indicated that the valve in question had been difficult to close during the previous iteration but that he believed it had been shut. Discussion continued regarding the combination of the two tanks and the only physical way the tanks could have been combined was if the valve for isolating Tank \#2 had not been fully closed and the two tanks were combined and recirculated back into Tank \#1 on July 16 , 2015.

A re-entry was made and it was verified that the valve from Tank \#2 had not been fully seated, a deviation from the June performance of the procedure, allowing the contents of the two tanks to be combined into one. This resulted in a change of hazards controls for managing the non-RCRA waste tank and requiring both tanks to be disposed of as exceeding RCRA limits.

What We Can Learn: If problems with plant equipment are identified during work activities (such as the valve that was found to be difficult to close), it is imperative to communicate those problems to management so they can be assessed and repairs can be made.

\section{ATR 674-M-6 Diesel Generator Failure to Load} NE-ID--BEA-ATR-2015-0027 (Significance Category 3) On July 6, 2015, the 674-M-6 diesel generator was being started for the monthly surveillance per Detailed Operating Procedure (DOP)-8.3.1, Standby Diesel and Equipment Operational Test. The diesel generator automatically shut down due to a "Reverse Volts, Amps, Reactives (VARS) Shutdown."

The M-6 Diesel Generator was declared inoperable and engineering was contacted to investigate the cause. Engineering determined the cause to be spurious in nature. Annunciator procedure LARM-EDG-1D was followed and a second attempt was made to start and load the generator. The second attempt was successful and DOP-8.3.1 was completed satisfactorily.

Operability of the 674-M-6 Diesel Generator is a Safety Analysis Report (SAR) commitment to provide defense-indepth to the ATR 480 Volt Diesel Bus Battery-Backed Power system. Allowed inoperable time is limited to 14 days per calendar year when one of the diesel generators (670-M-42 or 670-M-43) is out of service. M-42 Diesel Generator was out of service during the time of the occurrence.

The cause of the event was determined to be an end of life failure of the reverse VARS relay and the normal aging process of the component. The relay was replaced.

\section{ATR West Canal Bulkhead Seal Failure}

NE-ID--BEA-ATR-2015-0028 (Significance Category 3)

On July 8, 2015, the ATR Canal Supervisor was making preparations for a cask handling evolution in the canal area when he informed the Shift Supervisor that air bubbles were visible from the west canal bulkhead. The seal pressure for one of the dual seals at this location also indicated that the seal was leaking. An investigation into the failure determined that the bulkhead seal has degraded, resulting in the leak.

ATR Technical Safety Requirements (TSR)-186 Limiting Condition for Operation (LCO)-3.5.5, PISA ATR Complex-USQ2010-741 interim controls and Technical Evaluation (TEV)284, Evaluation of the Safety of the Situation for ATR RTCUSQ-2008-451, requires that irradiated fuel elements in canal storage must be protected against potential canal draining accidents. Part of the protection provided to the irradiated elements in storage is to have isolation bulkheads installed in the canal with dual inflatable seals.

Cask handling in the canal was stopped. The cask was in a stable location on the main floor of the canal area and not in the actual canal when the seal failure was noted. Low pressure demineralized water makeup to the canal was confirmed to be available to the irradiated fuel storage section of the canal and door/bulkhead 51 was shut to provide additional separation between the canal and reactor interface as required by LCO-3.5.5, PISA ATR Complex-USQ2010-741, and TEV-284, Evaluation of the Safety of the Situation for ATR RTC-USQ-2008-451 action and interim controls. 
ATR M-10 Emergency Coolant Pump Inboard Seal Leak NE-ID--BEA-ATR-2015-0029 (Significance Category 4) On July 23, 2015, the M-10 Emergency Coolant Pump (ECP) inboard seal began leaking. At 1720, increased Primary Coolant System (PCS) leak rate was noted to be approximately 17 gallons per minute (gpm) and ATR Operations management was informed. Monitoring of the PCS leak rate continued and, at 1801, PCS leak rate elevated to approximately $30 \mathrm{gpm}$. The reactor was manually scrammed with Operations management concurrence. At 1813 , water was found on the floor of the bypass demineralizer room and at 2203, the leak was discovered to be coming from the M-10 ECP. At 2217, the M-10 ECP was isolated, successfully stopping the leak.

The ATR TSR require the M-10 ECP to be operable for power operations with the PCS pressurized, and forced flow for 30 minutes following a scram, per ATR TSR-186, Applicability, LCO-3.3.3.

At the time of discovery, ATR was in pressurized shutdown and fueled with Primary Coolant Pumps (PCPs) running. Greater than 30 minutes had elapsed after shutdown before the M-10 pump was isolated. M-10 ECP supplied the required flow even with the seal leaking. M-10 ECP was operable up to the point when it was isolated to stop the leakage.

\section{ATR M-11 Emergency Coolant Pump Trip}

NE-ID--BEA-ATR-2015-0030 (Significance Category 4)

On July 27, 2015, the M-11 ECP unexpectedly stopped running. Investigations found no abnormal problems, temperatures, or smells. The M-11 ECP breaker was not tripped and the Senior Reactor Auxiliary Operator (SRAO) was directed to open the M-11 supply breaker.

The ATR TSR require the ECPs to be operable for power operations with the PCS pressurized, and forced flow for 30 minutes following a scram, per ATR TSR-186, LCO-3.3.3. At the time of discovery, ATR was depressurized, shutdown, and fueled.

\section{ATR Log Count Rate Instrument Channel \#1 Recorder Pen Shift on Slide Wire}

NE-ID--BEA-ATR-2015-0031 (Significance Category 4)

On July 30, 2015, the ATR Log Count Rate Instrument Channel $\# 1$ recorder pen holder shifted on the slide wire during a change of the pen. A check of the instrument and recorder after the pen change discovered the issue. With one of two channels out of service, the required weekly surveillance checks on the remaining channel could not be performed.

ATR TSR-186, LCO-3.5.3, requires at least one Log Count Rate Instrument to be operable when the facility is in "Pressurized Standby," with two or more fuel elements in the reactor core. One channel of Log Count Rate instrumentation remained in service at all times.

\section{ATR 480 Volt Diesel Uninterruptible Power Supply Unit \#1 Inverter Trouble}

NE-ID--BEA-ATR-2015-0032 (Significance Category 4)

On August 21, 2015, ATR was recovering from a 670-E-3

electrical bus planned outage. While recovering, the $480 \mathrm{Volt}$ (V) Diesel Uninterruptible Power Supply (UPS), an alarm was received on the \#1 unit indicating inverter trouble. The UPS system was returned to maintenance bypass operation until the alarm codes and unit operation could be reviewed by Engineering. Several days later, Engineering reviewed their findings with ATR Management and it was determined that some type of component fault existed with the \#1 UPS that would prevent the inverter to supply the downstream electrical distribution system.

ATR TSR-186, LCO-3.4.4 requires the 480 V Diesel Bus Battery Backed Power System be available to bus 670-E-9 during "Power Operation" and 30 minutes following "Power Operation" when 670-E-3 is powered from 670-E-2. At the time of discovery, ATR was shut down and defueled with the UPS system in maintenance shutdown.

\section{ATRC Manual SCRAM Due to Rising Current on \#3 Safety Rod Actuator Controller}

NE-ID--BEA-ATR-2015-0033 (Significance Category 3) The Advanced Test Reactor Critical (ATRC) was shut down by manual scram on September 2, 2015, in response to increasing current on Safety Rod \#3 actuator controller. A normal reactor startup was in progress using Operating Procedure (OP)-1.2, ATRC Startup procedure when the magnet holding current on the \#3 Safety Rod actuator controller was observed to have drifted approximately 7 milliamps ( $\mathrm{mA}$ ) above the nominal setting. The nominal setting is $10 \mathrm{~mA}$ below the TSR maximum. The ATRC Supervisor consulted the ATR Operations Manager and elected to establish continuous monitoring of magnet current and continue the startup with a planned shutdown if magnet current increased by $9 \mathrm{~mA}$ ( $1 \mathrm{~mA}$ below the procedural and TSR limit). At 1121, magnet current reached $9 \mathrm{~mA}$ above nominal and the ATRC Supervisor directed a reactor shutdown by manual scram. 
Increasing magnet current has the effect of increasing safety rod release time upon receipt of a SCRAM signal. Facility surveillance procedures ensure that safety rod release time is within TSR specification as long as magnet current does not exceed the nominal setting by more than $10 \mathrm{~mA}$.

The reactor was shut down by manual scram when the preestablished abort criteria level was met and normal facility shutdown procedures were completed. The ATRC was shut down prior to reaching any limits. An actual unsafe condition did not exist.

\section{ATR Log Count Rate Instrument Channel \#1 Failed Calibration}

NE-ID--BEA-ATR-2015-0034 (Significance Category 4)

The ATR Log Count Rate Instrument Channel \#1 failed calibration on September 8, 2015. The instrument was not responding to signals input into the pre-amplifier. At the time of discovery, ATR was defueled.

ATR TSR-186, LCO-3.5.3 requires at least one Log Count Rate Instrument to be operable when the facility is in "Depressurized Shutdown," "Pressurized Shutdown," or "Pressurized Standby" with two or more "Fuel Elements" in the reactor core.

\section{ATR 674-M-6 Diesel Generator Failure to Load} NE-ID--BEA-ATR-2015-0035 (Significance Category 4) The 674-M-6 diesel generator was being started for the monthly surveillance per DOP-8.3.1, Standby Diesel and Equipment Operational Test, on September 11, 2015. The diesel generator automatically shut down due to a "Reverse VARS Shutdown."

Engineering and Operations management concurred with reperformance of DOP-8.3.1. Annunciator procedure LARMEDG-1D was followed and a second attempt was made to start and load the generator. The second attempt was successful and DOP-8.3.1 was completed satisfactorily.

ATR was shut down and defueled the time of the event. Operability of the 674-M-6 diesel generator is a SAR commitment to provide defense-in-depth to the ATR 480 Volt Diesel Bus Battery-Backed Power system. The redundancy provided by the 674-M-6 diesel is not required during the plant conditions at the time of this occurrence.

\section{ATR Neutron Level "B" Comparator Erratic}

NE-ID--BEA-ATR-2015-0036 (Significance Category 3) On August 7, 2015, ATR Neutron Level Bravo ("B") Plant Protective System (PPS) comparator became erratic and began processing an erroneous trip signal. Neutron level "B" is one of three channels that monitor reactor power and generates a SCRAM signal in the event that reactor power is too high. Per the ATR TSR-186, LCO-3.1.1A, neutron level "B" was placed out of service.

An investigation found the comparator Opto-isolator chip failed due to normal wear and tear. Opto-isolator failures over time are anticipated and replacement is done immediately.

\section{ATR Deep Well Pump \#1 Discharge Check Valve Stuck Open}

NE-ID--BEA-ATR-2015-0037 (Significance Category 4) On September 16, 2015, the ATR Control Room was notified that the \#1 Deep Well Pump (DWP) discharge check valve stuck open during testing on the \#3 DWP. The ground level storage tank level was not rising as expected with the \#3 DWP running. With the \#1 pump discharge check valve stuck open, flow from other deep well pumps and the ground level storage tanks flow back down the \#1 well. (Operators investigating the anomaly found water flowing back down the \#1 well.) The pump was started and stopped to reset the check valve.

ATR TSR-186, LCO-3.2.1.2, Emergency Firewater Injection Supply System, requires DWPs to be operable when the reactor vessel contains irradiated fuel elements. At the time of discovery, ATR was shut down and defueled. The emergency firewater injection system to the reactor vessel was not required to be operable.

\section{ATR Deep Well Pump \#3 Diesel Generator MP-3000 Protection Relay Failure}

NE-ID--BEA-ATR-2015-0038 (Significance Category R)

As stated on Page 8 of this report, on September 17, 2015, the ATR Shift Supervisor notified ATR management that the MP-3000 protection relay installed on the breaker for \#3 deep well pump (DWP) was discovered to have an error code which would prevent the DWP from starting.

The MP-3000 is a programmable circuit protection device that requires power to maintain its setpoint programming. The MP-3000 for the \#3 DWP is continuously powered by control power fed from TRA-608.

ATR management determined the event to be recurring based on two additional events that occurred on January 26, 2015, and again on April 20, 2015. In response to the second event, a temporary modification was installed to keep the relay powered at all times. The relay was also to be replaced; 
however, the newly ordered relay from Eaton arrived unacceptable for use. With the temporary modification still in place, it was believed that even though the condition of the relay was deteriorating, since it was now always powered, it would continue to perform.

The third failure indicated that the compensatory and corrective actions to address the first two failures were not effective in preventing another failure.

\section{ATR M-9 Primary Coolant Pump Breaker}

NE-ID--BEA-ATR-2015-0039 (Significance Category 4)

On August 14, 2015, when M-9 PCP Breaker was racked out for normal shutdown testing, a latching mechanism spring on the breaker assembly fell off. Without the spring, the breaker would not trip. At the time of this event, ATR was shut down and defueled with no PCPs running.

The ATR TSR-186 require the PCP breakers to trip as part of Engineered Safety Features (ESF) per LCO-3.2.3.1, when two or more PCPs are operating, and LCO-3.2.3.3 during "Power Operation" and following "Power Operation" until greater than $\mathbf{3 0}$ minutes has elapsed or until less than or equal to 1 $P C P$ is running.

\section{Other Non-Reportable Events}

There were two additional non-reportable event related to facility status reported during the $4^{\text {th }}$ Qtr FY-15. They are as follows:

\section{CO-2015-3007}

On July 25, 2015, the ATR was performing a normal PCS shutdown/depressurization. Emergency Firewater Injection System (EFIS) was drained, isolated, and in "Manual," in accordance with PCS shutdown/depressurization procedures. During the final portions of the shutdown procedure, the EFIS Level Control Valves (LCV) opened unexpectedly. PCS depressurization was stopped and Reactor Control Room (RCR) personnel investigated. Two of four bypass switches for EFIS actuation system were found in "Normal" vice the "Bypass" position. "Bypass" was the correct position for these switches during this phase of the PCS shutdown procedure.

An investigation into the event found that the DOP-7.3.19 had errors in the step for positioning the switches.
CO-2015-3007

On August 24, 2015, during preparations for performance of EFIS response time test a LO/TO that was hung for removing a check valve and installation of blind flanges was partially cleared to facilitate the response time test. Valves associated with the reactor bottom head flush system were repositioned per the LO/TO partial clearance. Repositioning these valves opened a flow path from the Warm Seal System to a portion of the EFIS piping where a blank flange should have been installed on one side of the removed check valve, as directed in the work order that removed the check valve.

Between 1801 and 1819 hours, warm seal system water, which is supplied by the primary coolant system flowed from the open piping at the removed check valve to the subpile room floor. Water loss from the primary coolant system was indicated by the Plant Protective System (PPS) Vessel level, which lowered from 93" to approximately 86." No alarms were received. The operations watch team promptly identified that they were losing water from the PCS and shut the valves causing the flow path. A Gland Seal Water pump was started and the system was returned to normal by 1830 . At the time of the event, ATR was shut down and defueled.

An apparent cause analysis of this event is ongoing.

\section{ANALYSIS FOR RECURRING EVENTS:}

Facility status occurrences were the most frequently reported event type, accounting for 45 reportable events in the last 12 months.

Thirty-two of the events in the past 12 months were the result of degradation of a safety class or safety significant component when the equipment was not required to be operable; all were discovered at the ATR facility. Discovery of these events occurred mostly because of maintenance activities performed in preparation for the reactor restart. Many of the events occurred because frequent foot traffic to the facility caused degradation of the door seals and latches. Additional problems were discovered because extended shutdown of equipment resulted in loss of backup battery capabilities.

ATR management found one event to be recurring (see discussion regarding NE-ID--BEA-ATR-2015-0038). A review of the other events by both ATR management and the ORPS program lead, found none others to be recurring issues. 


\section{TREND SNAPSHOT}

Environmental Events: There was one environmental event reported in the $4^{\text {th }}$ Qtr FY-15. The rate of occurrence of environmental events is trending downwards.

When compared to the balance of the DOE complex, the percentage of occurrence of Group 5, environmental events reported at INL is slightly higher than that of the balance of the DOE Complex ( $5 \%$ compared to $3 \%$ during FY-15). All of the environmental events reported during the last two years have been related to 40 CFR Part 63, Subpart ZZZZ (also known as Quad Z) requirement changes.
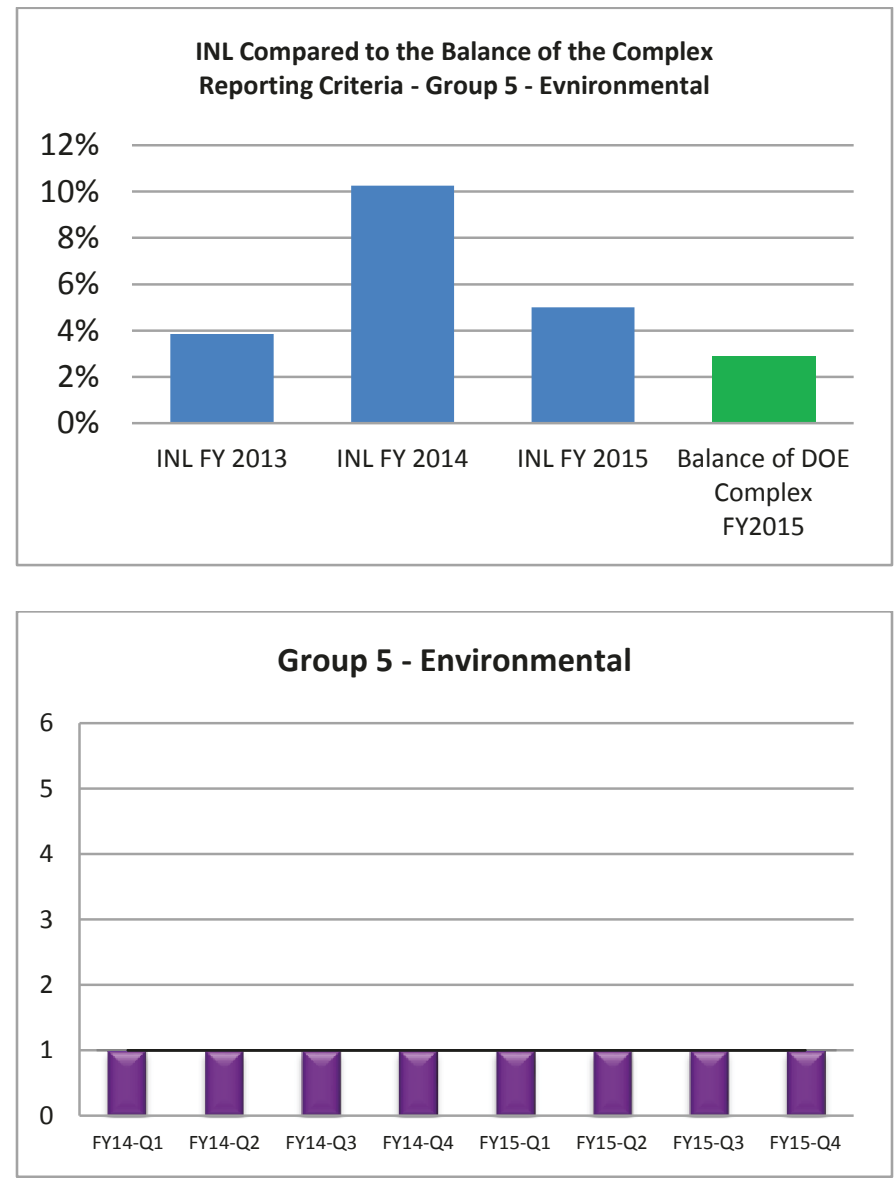

The one event reported in the $4^{\text {th }}$ Qtr FY-15 is described as follows:

\section{Quarterly Report of Diesel Engine Startup at the Advanced Test Reactor}

NE-ID--BEA-ATR-2015-0026 (Significance Category 4)

New environmental regulations, operation, and maintenance requirements for ATR Complex diesel engines are in effect: 40 CFR, Part 63, Subpart ZZZZ, National Emissions Standards for Hazardous Air Pollutants for stationary Reciprocating Internal Combustion Engines (RICE).

The following ATR Complex engines are non-emergency stationary RICE: Generators 670-M-42, 670-M-43, and 674-M6. Without installation of emissions controls, units $670-\mathrm{M}-42$, 670-M-43, and 674-M-6 do not meet the new emission standards for hazardous air pollutants that went into effect on May 2, 2013. INL has negotiated with the Idaho Department of Environmental Quality (DEQ), a Voluntary Consent Order (VCO) to replace units 670-M-42 and 670-M43 with a commercial power based UPS. When the UPS project is complete in 2015, all three units will be designated as emergency stationary RICE.

\section{Other Non-Reportable Events}

There was one additional non-reportable events related to environmental problems reported during the $4^{\text {th }}$ Qtr FY-15.

\section{CO-2015-3171}

On August 6, 2015, MFC Environmental personnel were walking along the west side of MFC reviewing the MFC fire water system construction activities when it was observed that a permitted industrial waste water ditch (Ditch C) had a trench cut through the ditch. The ditch was dammed to prevent water from entering the trench. MFC Environmental performed a review of the environmental checklist and found that the ditch had not been identified as an environmental aspect.

Some issues identified during the critique include: the ditch was not identified as permit required in the applicable Environmental Checklist; Construction personnel at the request of Security dumped slurry from earlier excavation 
into the ditch; planning of the work did not identify as a potential issue as to where to dump the dirt; the ditch is not posted as a permitted area and, therefore, not easily identifiable as such; no facility area drawings, under configuration control, identify areas that are permitted; and, definition of "modification" is not clearly defined in the permit, hence the phone call to the State DEQ.

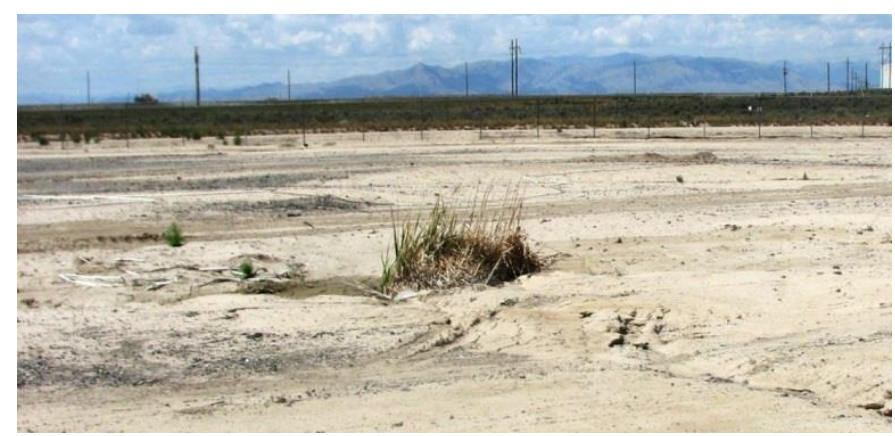

\section{What We Can Learn:}

Configuration management is essential for work planning and as equally important as the need to identify permitted structures and/or areas to provide defense in depth.

\section{ANALYSIS FOR RECURRING EVENTS:}

Although the reportable event reported this quarter is exact in nature to each of the other three events reported in the past 12 months, it is not indicative of an adverse trend or recurring problem, but is the result of changes to $40 \mathrm{CFR}$ Part 63. There were no additional non-reportable events during the past 12 months. 


\section{TREND SNAPSHOT}

Contamination/Radiation Events: There were no reportable event related to contamination/radiation control reported in the $4^{\text {th }} \mathrm{Q} \operatorname{tr} F Y-15$. The rate of these types of events is trending steady near zero over the past two years. During the last 12 months, only one reportable event was entered in ORPS. There was one non-reportable event documented this quarter.

Only one percent of the events reported at INL during FY-15 were reported under Group 6 Contamination/Radiation criteria. The balance of the DOE complex reported $6 \%$ of events under the same criteria. Events related to contamination and/or radiation control are some of the least reported event types at INL; these have only accounted for one event at INL in the last 12 months.

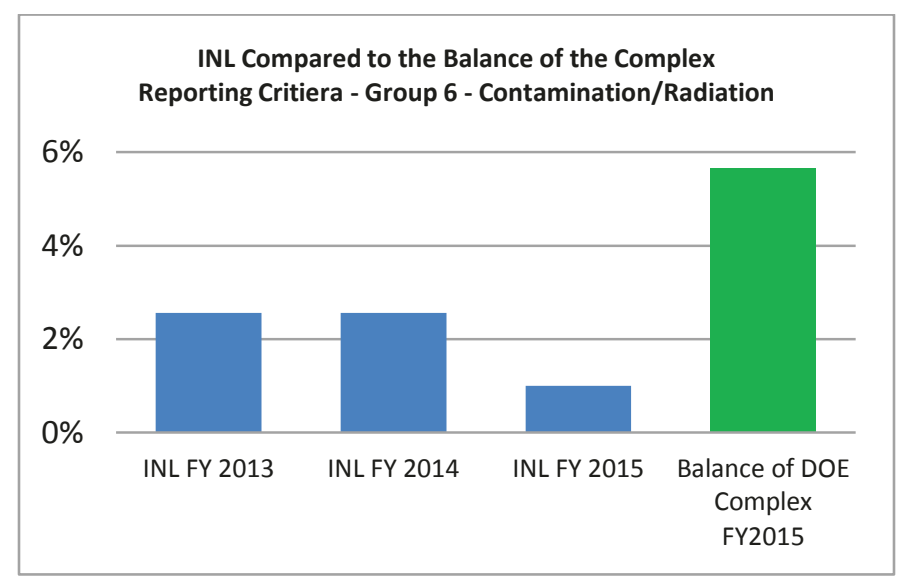

Group 6 - Contamination/Radiological Controls

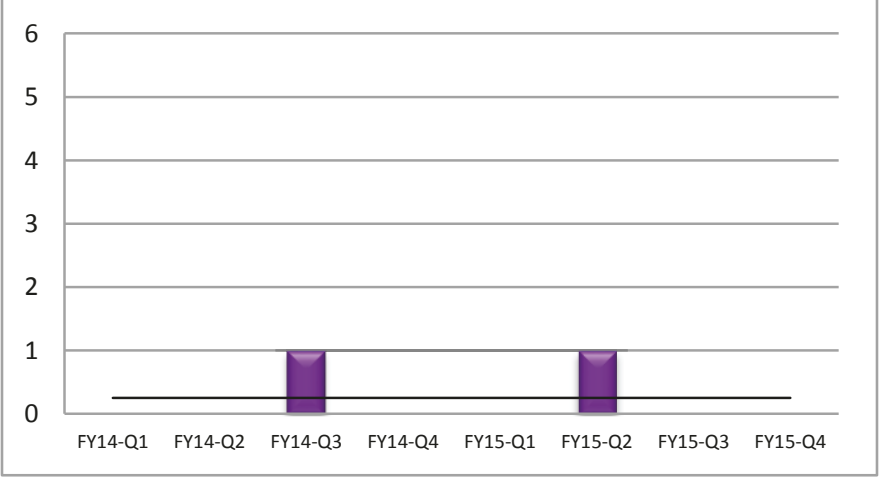

The non-reportable event is summarized below:

\section{Other Non-Reportable Events}

CO 2015-3400

On August 27, 2015, during exit surveys from an High Contamination Area (HCA), beta/gamma skin contamination was discovered in at least two areas on one individual. Area was surveyed with no additional contamination found and the individual was moved to a different facility for finalization of decontamination. The fact finding meeting determined that excessive perspiration and friction was a contributing factor to the event and that the stay time in the HCA was too long.

\section{What We Can Learn:}

When performing strenuous work while wearing PPE, we should consider the potential to compromise the integrity of the PPE by excessive perspiration and friction of the work being performed. This potential is enhanced if the time spent working in such conditions is great.

\section{ANALYSIS FOR RECURRING EVENTS:}

There has only been one reportable event under the Radiation/Contamination reporting criteria the past 12 months and three non-reportable events. A review of these four events identified no commonalities, no adverse trend, and no recurring problems. 
There were no events related to nuclear explosive safety during the $4^{\text {th }}$ quarter FY-15. BEA has never reported an event under this reporting criteria since taking over the contract for the Laboratory in 2005. There were two events reported under the Group 7 Nuclear Explosive Safety Events criteria across the DOE Complex during FY-15.

\section{$4^{\text {th }}$ Qtr FY-15 GROUP 8 - PACKAGING AND TRANSPORTATION EVENTS}

\section{TREND SNAPSHOT}

P\&T Events: There were no reportable P\&T during the $4^{\text {th }}$ Qtr FY-15. The rate of occurrence of P\&T issues is declining. Over the past 12 months, there has only been one P\&T-related reportable events documended in ORPS. One nonreportable P\&T event occurred during the $4^{\text {th }}$ Qtr FY-15.
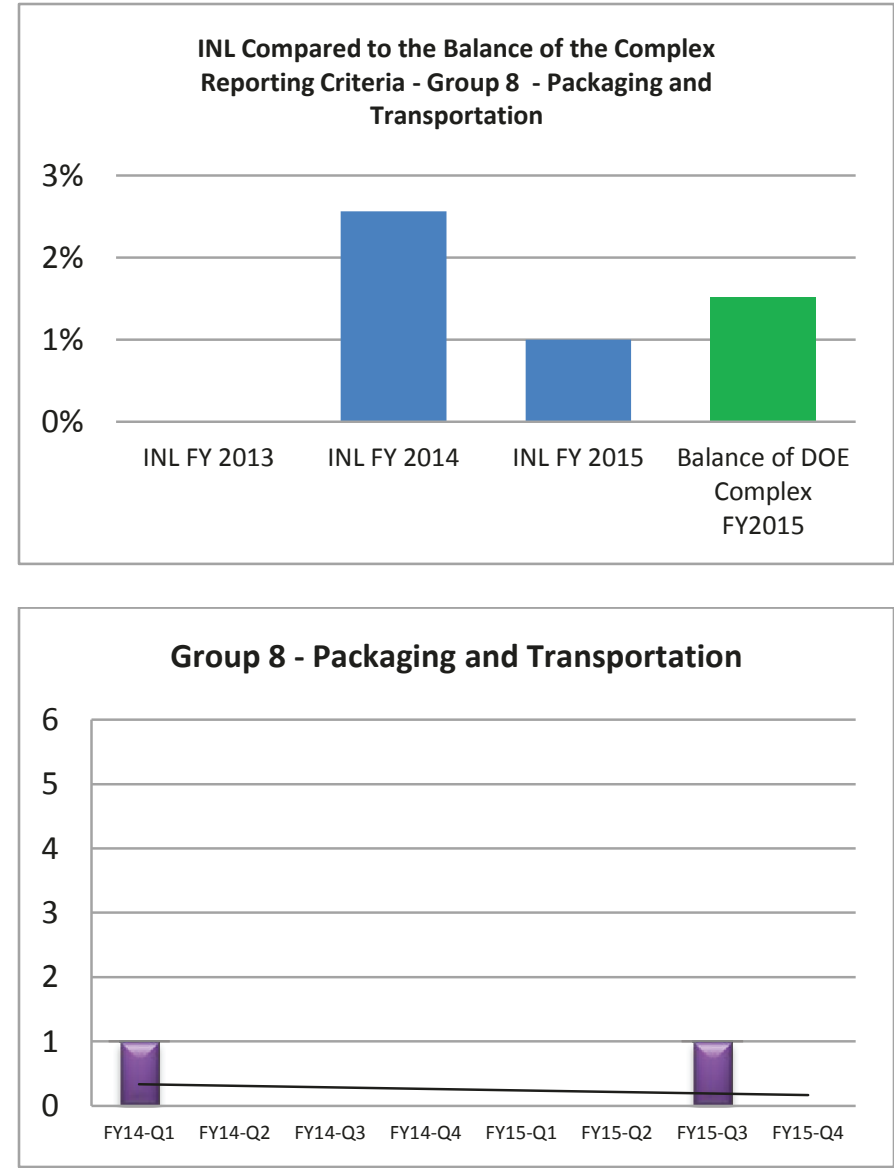

INL rarely reports events under Group 8 P\&T criteria. When compared to the balance of the DOE Complex, $1 \%$ of all INL reportable events documented in ORPS, during the FY-15, were related to $\mathrm{P} \& \mathrm{~T}$, vs $2 \%$ across the DOE Complex.

In the $4^{\text {th }}$ Qtr FY-15, INL did not report any P\&T events through ORPS, but did experience one event that was not reportable. This non-reportable event is summarized below.

\section{Other Non-Reportable Events}

CO 2015-3774

The National Nuclear Security Administration Nevada Field Office Radioactive Waste Acceptance Program suspended the BEA INL Waste Certification Program (WCP) from disposal of waste at the Nevada National Security Site (NNSS) due to shipping waste unapproved for disposal. The decision to suspend shipping of waste was the result of three separate waste shipments; each shipment contained fissile waste packaged in one USA/9979/AF-96 55 gallon drum (herein known as 9979) and disposed of in the NNSS Area 5 disposal cell. The 9979 containers were filled at the MFC at INL and were shipped to NNSS on September 23, 2014, January 12, 2015 , and April 7, 2015. The scope of this cause analysis is limited to the events that led up to or allowed the shipment of the three 9979 containers without ensuring the containers were included on the INL waste profile and without ensuring the proper safety basis was in place prior to shipment.

The fissile material was generated in the MFC Fuels and Applied Science Building (FASB). Three separate shipments, each containing one of USA/9979/AF-96 55 gallon drum, 
were made from INL to the NNSS on September 23, 2014, January 12, 2015, and April 7, 2015. The shipments were coordinated by a Waste Disposition Specialist (an

EnergySolutions employee) who, during the latter part of April and the early part of May, began to question the shipments and the methods used to validate that the packaging and its contents were compliant with INL's approved waste profile for shipments to NNSS. In early September 2015, prior to a fourth shipment using the 9979 drums, the Waste Disposition Specialist shared the concern with EnergySolutions management.

On September 23, 2015, it was determined and disclosed that the three previous shipments were non-compliant and should not have been made using the 9979 drums as the use of the drums was not identified on INL's waste profile and the manner in which the waste was packaged was not compliant with the NNSS Waste Acceptance Criteria (NNSSWAC).

The NNSSWAC states that the quantity of fissile material in any waste package shall be limited so that an infinite array of such packages would be subcritical under the "as packaged" conditions and if the array were to be flooded with water while stored at NNSS. In order to meet this requirement, the WAC states that the packages shall comply with the fissile material limits specified in Appendix E of the WAC and that the fissile material limits shall be documented in the site's waste profile. The methods used to qualify the drums for compliance with the waste profile and the NNSSWAC had been reviewed and accepted by the Alternate Waste Certification Official (WCO) during the review of the September 23, 2014, drum shipment.

An analysis into the event found that training did not prepare personnel to fully understand the NNSSWAC and the INL waste profile. Additionally, procedures did not ensure personnel performed necessary actions to verify the packages compliant. Personnel also exhibited a lack of questioning attitude and failed to perform independent reviews of packaging documents.

\section{What We Can Learn:}

When performing work, it is imperative that anomalies are fully understood and are properly vetted through knowledgeable personnel.

\section{ANALYSIS FOR RECURRING EVENTS:}

There is no indication of an adverse trend or recurring problems associated with P\&T activities at INL.

\section{$4^{\text {th }}$ Qtr FY-15 GROUP 9 - NONCOMPLIANCE NOTIFICATIONS EVENTS}

\section{TREND SNAPSHOT}

Noncompliance Notification Events: Noncompliance notification events are reported when the INL receives written notification from an outside regulatory agency that the site or an INL facility is considered to be in noncompliance with a schedule or requirement. Over the past 12 months, the INL has not been issued any noncompliance notifications. There were no events reported under this criteria during the $4^{\text {th }} \mathrm{Q}$ tr FY-15. The two year trend data for these types of events shows a decreasing trend. 
Four percent of the events occurring during FY-15, throughout the balance of the DOE Complex, were reported under this reporting criteria. None have been reported by INL during FY-15.

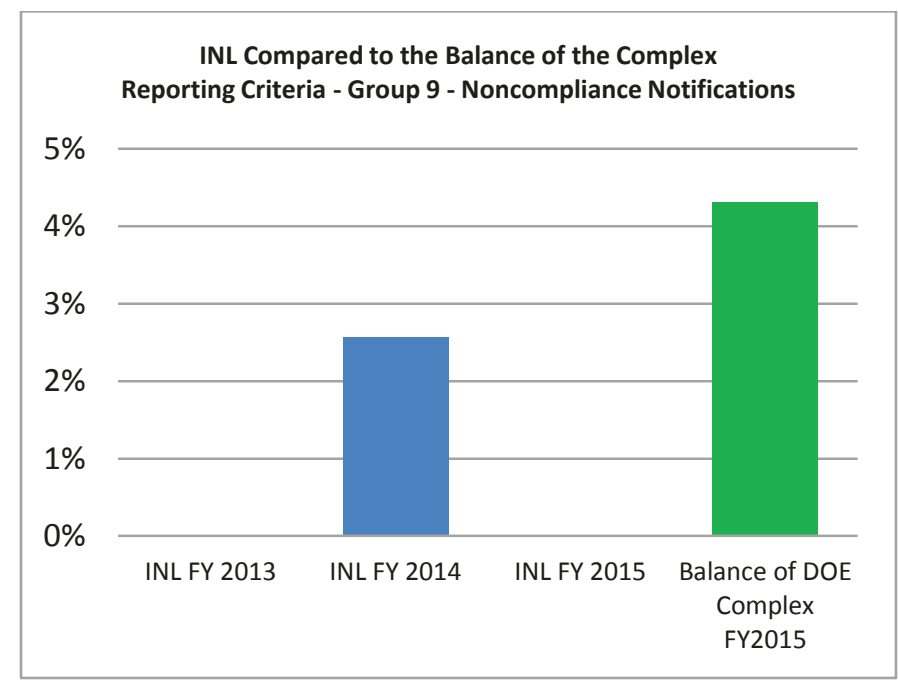

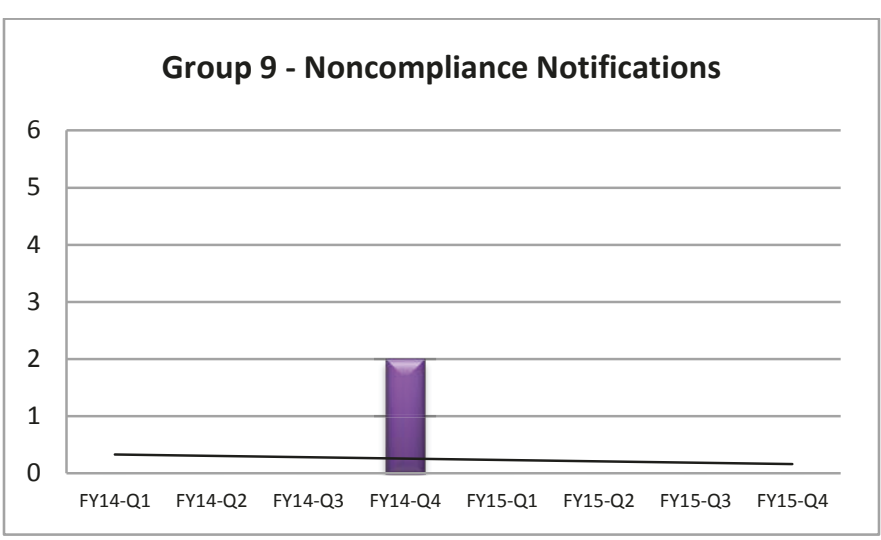

\section{Other Non-Reportable Events}

There were no additional non-reportable events related to noncompliance notifications reported during the $4^{\text {th }} \mathrm{Qtr}$ FY-15.

\section{ANALYSIS FOR RECURRING EVENTS:}

As stated in previous quarterly reports, there is no indication of an adverse trend or recurring problems associated with noncompliance notification reportable events at INL.

\section{$4^{\text {th }}$ Qtr FY-15 GROUP 10 - MANAGEMENT CONCERNS AND ISSUES}

\section{TREND SNAPSHOT}

Management Concerns and Issues: One event was reported during the $4^{\text {th }}$ Qtr FY-15, under reporting criteria for a management concern or issue. The rate of occurrence of reportable management concerns is trending upwards over the past two years. During the past 12 months, INL has reported 12 events under Group 10 management concerns.

The balance of the DOE complex reported $29 \%$ of all events, so far, in FY-15, under Group 10 Management Concern criteria. In comparison, INL has reported $14 \%$ of all events under Group 10 reporting criteria.

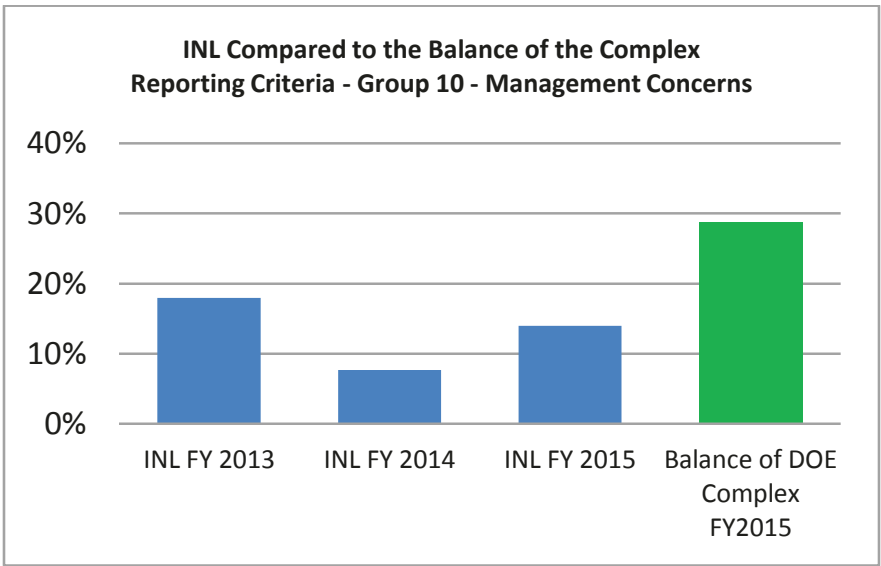




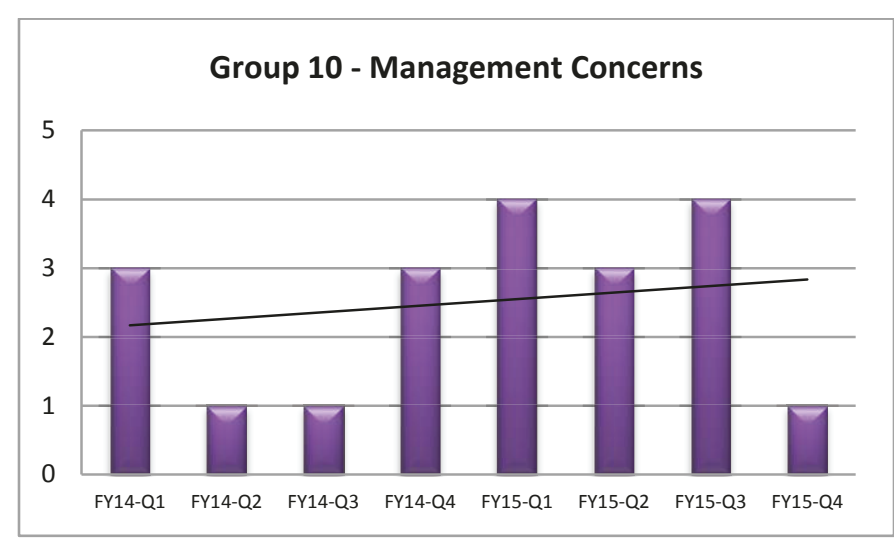

The one event reported during the $4^{\text {th }}$ Qtr FY-15 is summarized below:

\section{REC Fiber Optic Upgrade}

NE-ID--BEA-STC-2015-0004 (Significance Category 4)

An INL CFR was notified that a subcontractor working near EIL had concerns related to a sprinkler line the subcontractor apparently came in contact with during excavation, in preparation for core drilling into a utility vault.

Upon arrival, the CFR resolved the sprinkler concern and, while still at the work site, observed a subcontracted individual core drilling into a concrete utility vault without proper PPE. OSHA requires safety glasses, respiratory protection, and hearing protection be worn during performance of such work. None of the required PPE was being worn by the worker.

The CFR requested a copy of the subcontractor's work control document but the subcontractor did not have one in their possession. The CFR and the EIL Building Specialist contacted Research and Education Campus (REC) facility management, who directed them to stop work.

Follow-on meetings were held to understand the scope of the work and responsibility for work control. A formal stop work was initiated for this project, including scope at all other INL facilities/areas until contractual issues are resolved.

INL Industrial Hygiene evaluated the potential exposure to the worker. Using conservative calculations, the Hygienist indicated that the worker's exposure to silica dust did not exceed Threshold Limit Values (TLVs) and did not constitute a reportable exposure
What We Can Learn: When subcontractors employ additional subcontractors to perform work, it is important to ensure proper oversight of work is defined and executed. However, this can be difficult if employees do not understand who has jurisdiction over work being performed when the boundaries are not clearly understood. As in this event, the work was being performed in a utility corridor and personnel did not know if the City of Idaho Falls or the INL owned the utility corridor within property around INL leased facilities. Until these boundaries are understood, the appropriate roles and responsibilities for work control cannot be defined and communicated.

\section{Other Non-Reportable Events}

There were no additional non-reportable conditions that are being addressed as management concerns.

\section{ANALYSIS FOR RECURRING EVENTS:}

During the past 12 months, there have been 12 events that did not meet ORPS reporting criteria thresholds but were reported as management concerns or were categorized as near misses to a more significant event. Six reported as not meeting thresholds were:

- LO/TO inadequacies at the MFC

- CFA-623, Malfunction of Equipment

- $\quad$ ATR Transmitter Drain Header Burst During Venting

- Identification of a Recurring Theme within the INL Power Management Group

- $\quad$ REC Fiber Optic Upgrade

Seven additional events have been reported as near misses during the past 12 months. These include:

- Conduit Damaged During Core Drilling Activities

- $\quad$ Stop Sign Pole Snaps While Being Straightened

- Worker Exposed to Fall Hazard During Crane Preventative Maintenance

- $\quad$ TRA-666 Safety \& Tritium Applied Research Facility Sample Shipment

- Electrical Arc Due to Partition Adjustment

- Arc Flash at the CFA Substation

- Wild Land Fire Response Electrical Hazard Near Miss

After reviewing each event, there is no indication of an adverse trend or recurring problems associated with any of the events being reported as management concerns over the last 12 months. 


\section{TREND SNAPSHOT}

Events Involving Subcontractors: One of the reportable events this quarter involved subcontract employees. The number of reportable occurrences involving subcontractors is trending upwards due to three events in the $1^{\text {st }} Q \operatorname{tr} F Y-15$ and two events in the $2^{\text {nd }}$ Qtr FY-15. During FY-15, 8\% of INL's reportable events involved subcontractors. In comparison, $14 \%$ of events occurring throughout the balance of the DOE complex involved subcontracted personnel.

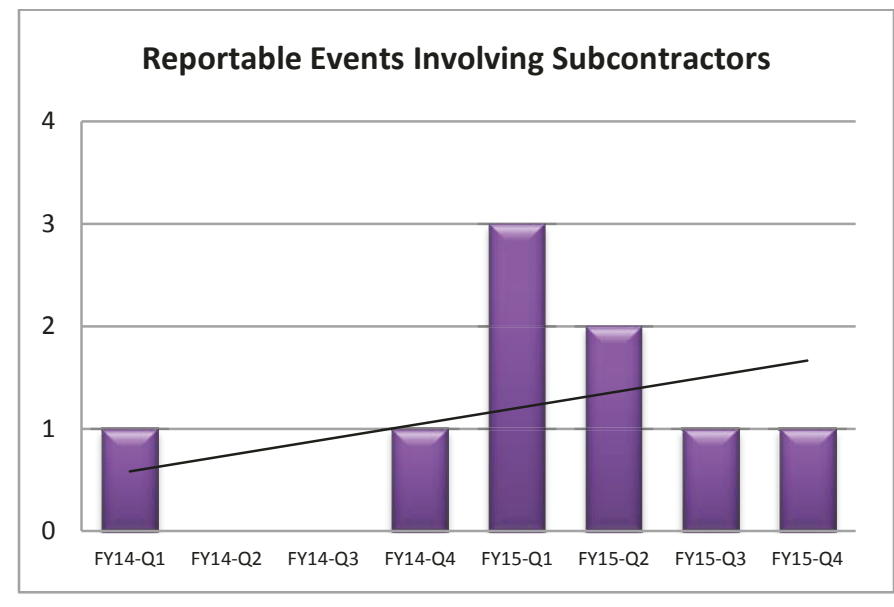

There have been seven ORPS reportable events involving subcontractors during the past 12 months. This quarter, the
REC Fiber Option Upgrade event (described on page 25) was the only event involving subcontract personnel.

\section{ANALYSIS FOR RECURRING EVENTS:}

The events of the past year were reviewed for similarities; none were identified. One subcontractor has been involved in three of the seven events during the last 12 months; however, there is no indication of a recurring problem or adverse trend associated with this subcontractor.

Additionally, there is no indication of an adverse trend or recurring problem associated with any of the events involving subcontract personnel that have occurred over the last 12 months.

\section{$4^{\text {th }}$ Qtr FY-15 ANALYSIS OF CAUSES OF REPORTABLE EVENTS}

Cause codes documented in ORPS were analyzed through ORPS distribution trend reports to get an understanding of what is causing or contributing to events at INL. The data was reviewed to determine causes over the 12 months and the past 24 months. Cause codes are not required to be entered into ORPS for Significance Category 4 events, so data from those events is not included in this analysis.

The analysis shows that the majority of causes over both time periods can be attributed to management (A4), human performance (A3), and equipment and materials problems (A3). INL has seen a reduction in the events caused in part by less-than-adequate communications (either written or verbal). The distribution of causes remained somewhat consistent. Successful mentoring and oversight, achieved by having management spend time in the field, watching work, and addressing incorrect behaviors before they lead to events can help prevent these types of errors. INL expects improvement in these areas as the Management Observation Program (MOP) is rolled out across the Laboratory.

A comparison of the causes of INL events to the causes of events reported by the balance of the DOE Complex for the past two years show that the balance of the Complex reported $33 \%$ of the events occurred due, in part, to management problems followed by $23 \%$ of events caused by less-than-adequate human performance. 


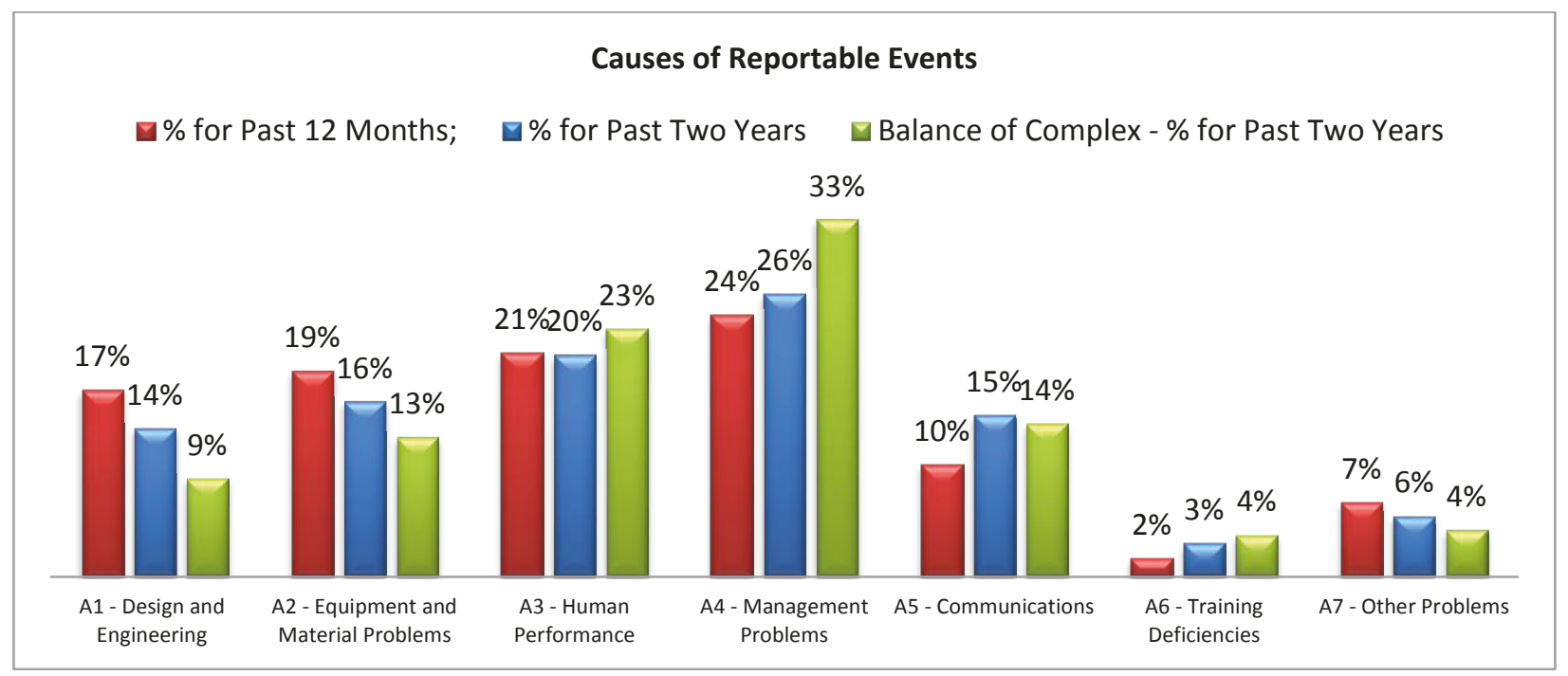

In addition to evaluating the cause of events, INL analyzes each reportable event to identify where we failed to effectively implement the five Integrated Safety Management System (ISMS) core functions. The chart below shows all reportable events that have occurred over two separate intervals; the past 12 months, and the past 24 months. The chart also compares INL's reporting of ISMS failures to that of the balance of the DOE Complex. For the purpose of the chart, ISMS Core Functions are defined as:

- $\quad$ CF1 - Define the Scope of Work

- $\quad$ CF2 - Identify the Hazards

- CF3 - Develop and Implement Hazard Controls

- CF4 - Perform Work Within Controls

- $\quad$ CF5 - Provide Feedback and Continuous Improvement

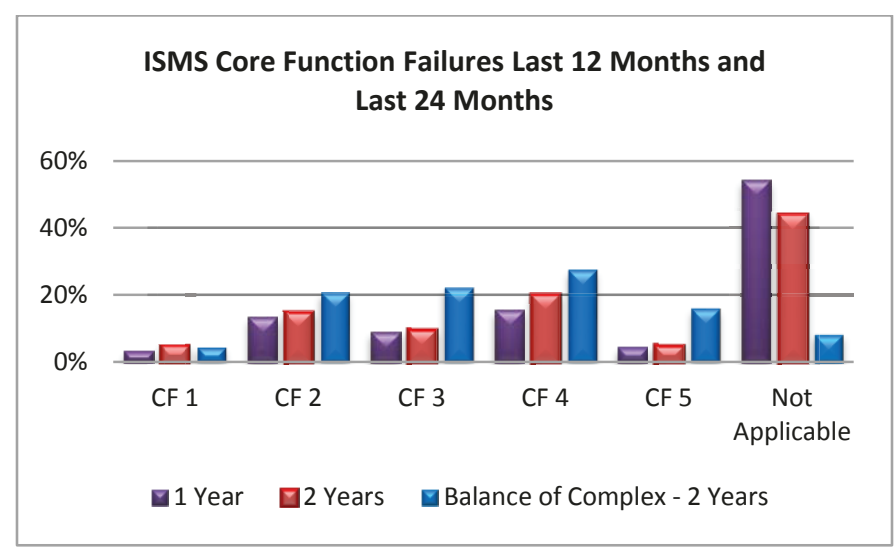

Over the past year, $54 \%$ of INL reportable events indicated no known failures of the ISMS process. These events include equipment problems and discovery of suspect counterfeit parts among other events. Sixteen percent of the events indicated problems with Core Function 4 - Perform Work within Controls. This is a $4 \%$ decrease from the two year comparison. These metrics will continue to be monitored to ensure INL is effectively implementing the ISMS program.

The INL MOP has been enhanced so that it can enable safe, secure, efficient, and effective work performance through regular, purposeful, and documented management presence, where and when employees perform work. This is achieved by management personally observing work activities and communicating with employees to solicit input and provide mentoring, coaching, and timely feedback on behaviors. This program strengthens application of Core Function 4 and is almost fully implemented across the INL. 


\section{TREND SNAPSHOT}

IOPAC Trending Analysis: The INL Integrated Operations Performance Analyses Committee (IOPAC) was formed by the INL Oprations Council to provide a forum to discuss Laboratory-wide trends (both adverse and positive) with a goal of elevating Laboratory level risks to the Operations Council. This was done at the mission centers. During the $4^{\text {th }} \mathrm{Q} \operatorname{tr} F Y-15$, the IOPAC changed hands and, with the transfer of responsibility, a change of approach in analysis. The new path forward will be to provide a forum for Management System and key operational program leads to discuss adverse and positive trends noted in implementation of systems/programs at INL.

The IOPAC summary for the $4^{\text {th }}$ Qtr FY-15 included the following items:

- Contractor Assurance System (CAS): Laboratory Protection Management Review Meeting/CAS process is positive example for the Laboratory; all levels of leadership/management are engaged; top down/bottom up approach applied. CAS is valued.

- Environmental: Batteries and lightbulb disposal issues due to lack of awareness and understanding. Mostly at ATR and MFC. Mitigation: Localized trainings offered at ATR and MFC (available to all where issues identified); all mission centers informed of issue through IOPAC.

- Environmental: Permitting and late notification to facilities impact. Mitigation: Lessons Learned for Environmental to engage Mission Organizations earlier in process; MFC responding to ensure appropriate personnel have HAZWOPER training.

- Quality: Quality Engineering resource is lacking for Energy and Environment Science \& Technology (EEST)/National Homeland Security (NHS). Mitigation: Job postings are forthcoming: shared resource for EEST/NHS.

- Radiological Controls: BEA assumed dosimetry programs from other site contractors on Oct. 1 and noted an inconsistency in dosimeters. Mitigation: BEA RadCon is evaluating dosimeters for Beta, Gamma, and Neutron coverage.

- Work Management: Noted spike in related issues at ATR in planning work packages and schedule delays. Mitigation: Increased communications and integration

- Human Performance Improvement (HPI): Noted that MFC had 100\% residence trained; training included elements of safety culture.

- Laboratory Employee Safety Team (LEST): Discussed success of SMC onboarding program.

- $\quad$ MFC: Discussed success of improvement Initiatives and getting ahead of issues (i.e., finding things before they bite us by engaging line level to identify potential issues). Bottom up and top down approach.

- Self-Assessments: Currently, validating concern with assessment quality. Working to ensure we have alignment with a standard expectation of quality of assessments. DOE generally has agreed with our measurements but do we have a complete understanding of what good looks like? Integrated Assessment System (IAS) sun setting concern to ensure all records are moved to the Electronic Document Management System (EDMS). Mitigation: Working fix and will report next meeting.

- $\quad$ LO/TO: Working change of procedure to be piloted at MFC. Realize changing procedure can be error precursor; as such, we need to be aware and we need to increase communications. This change is not changing execution of LO/TO, but rather making the process more "worker friendly."

- Hoisting and Rigging: Issuing a guide for Material Handling; modifying the procedures to separate Fork Lifts from general Hoisting and Rigging. Laboratory Protection implemented a weight labeling so worker knows the load prior to attempting the lift. 


\section{INL Quality and Performance Management Expectations}

INL has a vision to change the world's energy future and secure our critical infrastructure. INL's mission is to discover, demonstrate and secure innovative nuclear energy solutions, other clean energy options and critical infrastructure. Quality and Performance Management plays a critical role in supporting the INL mission. Our mission is to:

- Ensure we as a Lab know how we are doing and are improving our performance.

- Own and manage the Laboratory Issues Management System.

- Provide high quality QA program support for research and operations.

- Provide effective independent oversight.

"In order to be successful, we must be leaders, we must be competent, and we must be accountable. We must also exhibit the INL values of excellence, integrity, ownership, and teamwork."

- Chris Hott, Director - INL Quality and Performance Management 